\title{
Doxorubicin-loaded aromatic imine-contained amphiphilic branched star polymer micelles: synthesis, self-assembly, and drug delivery
}

This article was published in the following Dove Press journal:

International Journal of Nanomedicine

18 May 2015

Number of times this article has been viewed

\section{Liang Qiu \\ Chun-Yan Hong \\ Cai-Yuan Pan}

Chinese Academy of Sciences Key Laboratory of Soft Matter Chemistry, Department of Polymer Science and Engineering, University of Science and Technology of China, Hefei, Anhui, People's Republic of China
Correspondence: Cai-Yuan Pan;

Chun-Yan Hong

Chinese Academy of Sciences Key Laboratory of Soft Matter Chemistry, Department of Polymer Science and Engineering, University of Science and Technology of China, Hefei Anhui 230026, People's Republic of China

Tel +86 55I 63603264 ;

+8655I 6360608 I

Email pcy@ustc.edu.cn; hongcy@ustc.edu.cn
Abstract: Redox- and pH-sensitive branched star polymers (BSPs), BP(DMAEMA-coMAEBA-co-DTDMA)(PMAIGP) $\mathrm{s}$, have been successively prepared by two steps of reversible addition-fragmentation chain transfer (RAFT) polymerization. The first step is RAFT polymerization of 2-(N,N-dimethylaminoethyl)methacrylate (DMAEMA) and p-(methacryloxyethoxy) benzaldehyde (MAEBA) in the presence of divinyl monomer, 2,2'-dithiodiethoxyl dimethacrylate (DTDMA). The resultant branched polymers were used as a macro-RAFT agent in the subsequent RAFT polymerization. After hydrolysis of the BSPs to form BP(DMAEMAco-MAEBA-co-DTDMA)(PMAGP) $\left.)_{\mathrm{n}} \mathrm{(BSP-H}\right)$, the anticancer drug doxorubicin (DOX) was covalently linked to branched polymer chains by reaction of primary amine of DOX and aldehyde groups in the polymer chains. Their compositions, structures, molecular weights, and molecular weight distributions were respectively characterized by nuclear magnetic resonance spectra and gel permeation chromatography measurements. The DOX-loaded micelles were fabricated by self-assembly of DOX-containing BSPs in water, which were characterized by transmission electron microscopy and dynamic light scattering. Aromatic imine linkage is stable in neutral water, but is acid-labile; controlled release of DOX from the BSP-H-DOX micelles was realized at $\mathrm{pH}$ values of 5 and 6 , and at higher acidic solution, fast release of DOX was observed. In vitro cytotoxicity experiment results revealed low cytotoxicity of the BSPs and release of DOX from micelles in HepG2 and HeLa cells. Confocal laser fluorescence microscopy observations showed that DOX-loaded micelles have specific interaction with HepG2 cells. Thus, this type of BSP micelle is an efficient drug delivery system.

Keywords: RAFT polymerization, controlled release, doxorubicin, branched star polymer, $\mathrm{pH}$-sensitive

\section{Introduction}

In the past decades, various drug delivery approaches have been developed to achieve target delivery, highly therapeutic efficacy, and minimal side effects. ${ }^{1}$ As one of the most promising nanocarrier systems, self-assembled polymeric micelles have attracted significant attention due to their unique features, such as enhancing aqueous solubility of the drug, prolonging circulation time, reducing systemic adverse effects, and preferential accumulation at the tumor site owing to the enhanced permeability and retention effect. ${ }^{2-6}$ Various architectural polymers including linear polymers, dendrimers, hyperbranched polymers, and dendronized polymers have been utilized to construct nanocarriers. ${ }^{7-11}$ Compared to the linear polymers, branched polymers possess some advantages, including a number of surface groups and hollow voids of the branching architecture, which make them attractive in drug delivery applications. ${ }^{12-16}$ 
Generally, there are two strategies to prepare the hydrophobic drug-loaded polymeric micelles; one strategy is encapsulation of the drug within the hydrophobic cores of micelles or nanoparticles, ${ }^{17-19}$ and the resultant products can improve the water-solubility and enhance the stability of drug. ${ }^{20}$ The other strategy is to link the drug onto the hydrophobic core of micelles via a labile linkage that can be cleaved in the presence of external stimuli, such as redox state of the media, light, and specific molecules, and then the drug is released under environmental stimuli. ${ }^{21-24}$ For example, controlled release of the drug from nanostructural materials was achieved via the breaking of a photo-cleavable linker, 2-nitrobenzyl ester, under irradiation of $365 \mathrm{~nm}$ light, ${ }^{21}$ or via the breaking of reducible disulfylbutyrate linker in the presence of glutathione. ${ }^{22}$ Among the stimuliresponsive nanostructural materials, the $\mathrm{pH}$-sensitive polymeric assemblies have attracted extensive interest because of their particular relevance in biological applications and the significantly lower $\mathrm{pH}$ of the tumor cells as compared to normal cells. ${ }^{25,26}$ The acid-labile linkages utilized to chemically conjugate drugs onto the polymers or assemblies include

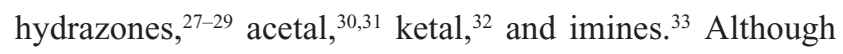
the acidic hydrolysis of imines is well known in organic chemistry, this imine linker is rarely utilized to conjugate drugs onto polymeric assemblies, because this linker has been reported to cleave at physiological $\mathrm{pH} .{ }^{34,35}$

In recent years, the imine linkers have gained significant attention, because several studies indicate that the aromatic imines with extended $\pi-\pi$ conjugation can significantly improve the stability of imine linkages in water. ${ }^{36-39}$ Therefore, we speculated that investigation of $\mathrm{pH}$-responsive behaviors of drug carriers, in which the drug is covalently attached to the polymer backbone in the hydrophobic cores via aromatic imine linkage, should be interesting, and would help to enable design of a $\mathrm{pH}$-triggered drug delivery system. The imine linkage has been widely employed in the preparation of shell or core cross-linked (SCL or CCL) micelles for improvement of micellar integrity and drug encapsulation stability. Encapsulation of a drug in CCL or SCL micelles was conducted through the reaction of primary amines in the polymers with a dialdehyde crosslinker. ${ }^{40,41}$ CCL and SCL micelles are also prepared by the reaction between linear polymers carrying the primary amine and aldehyde group, respectively. ${ }^{42,43}$ However, no report in the literature we consulted studies synthesis of polymeric micelles containing reactive aldehyde groups in core polymers for conjugation of molecules, eg, drug, peptides, or carbohydrates. Thus, a known aldehyde-containing monomer, p-(methacryloxyethoxy)benzaldehyde (MAEBA) was chosen in order to incorporate reactive aromatic aldehyde groups into polymer chains, and then an anti-cancer drug, doxorubicin (DOX) was covalently attached to the polymer chains by reaction of aldehyde in the polymer chains with the primary amine of DOX.

Very few studies on synthesis of copolymers containing MAEBA units have been reported; ${ }^{44-46}$ for example, reversible addition-fragmentation chain transfer (RAFT) polymerization of MAEBA and oligo(ethylene glycol) monomethyl ether methacrylate (OEGMA) produced water soluble random copolymers, and their thermo-responsive properties were studied. ${ }^{44}$ The block copolymer, poly(caprolactone)(PCL)- $b$-poly(OEGMA-co-MAEBA) was synthesized by atom transfer radical polymerization. ${ }^{45}$ All of these polymers used in the studies are linear; no study on branched copolymers containing MAEBA has been reported, to the best of our knowledge.

In the present article, we synthesize $\mathrm{pH}$ and redox dualresponsive micelles based on the branched star polymers (BSPs) containing biodegradable disulfide linkages through two steps of RAFT polymerization, as shown in Figure 1. The branched polymers are composed of MAEBA, 2,2'dithiodiethoxyl dimethacrylate (DTDMA), and 2-(N,Ndimethylaminoethyl)methacrylate (DMAEMA). The disulfide is a well-known reduction-responsive linkage, ${ }^{24,45}$ thus, degradation of the DTDMA units can ensure renal clearance of the polymers after drug delivery. The anti-cancer drug DOX was grafted onto the BSP by the reaction of the aldehyde group in MAEBA with the primary amine in DOX to form an acidic-labile imine bond. After self-assembling of the resultant BSPs in water, micelles with a DOX-containing branched polymer as a core and poly(6-O-methacryloyl-Dgalactopyranose) (PMAGP) as a shell were formed. Since the galactosylated units of PMAGP in the shell of micelles are selectively recognized by asialoglycoprotein receptor (ASGP-R) on the surfaces of HepG2 cells, ${ }^{24}$ the dual-responsive BSP micelles possessed a target delivery property.

\section{Materials and methods}

6-O-Methacryloyl-1,2; 3,4-di-O-isopropylidene-Dgalactopyranose (MAIGP) was prepared as previously reported, ${ }^{24}$ and its hydrogen-1 NMR ( $\left.{ }^{1} \mathrm{H}-\mathrm{NMR}\right)(300 \mathrm{MHz}$, $\mathrm{CDCl}_{3}, \delta$, ppm) was as follows: $1.21-1.60\left(\mathrm{~m}, 12 \mathrm{H},-\mathrm{CH}_{3}\right)$; $1.95\left(\mathrm{~s}, 3 \mathrm{H},-\mathrm{CH}_{3}\right) ; 4.08,4.19-4.42,4.63$, and 5.54 $\left(7 \mathrm{H}\right.$, sugar moiety); and 5.57 and $6.14\left(\mathrm{~s}, 2 \mathrm{H},=\mathrm{CH}_{2}\right)$. p-(methacryloxyethoxy)benzaldehyde (MAEBA) was prepared according to the reported procedure, ${ }^{43}$ and its ${ }^{1} \mathrm{H}-\mathrm{NMR}\left(300 \mathrm{MHz} \mathrm{CDCl}_{3}, \delta\right.$, ppm) was as follows: 1.92 $\left(\mathrm{s}, 3 \mathrm{H},-\mathrm{CH}_{3}\right) ; 4.29\left(\mathrm{t}, 2 \mathrm{H},-\mathrm{O}-\mathrm{CH}_{2}\right) ; 4.51\left(\mathrm{t}, 2 \mathrm{H},-\mathrm{O}-\mathrm{CH}_{2}\right)$; 
A

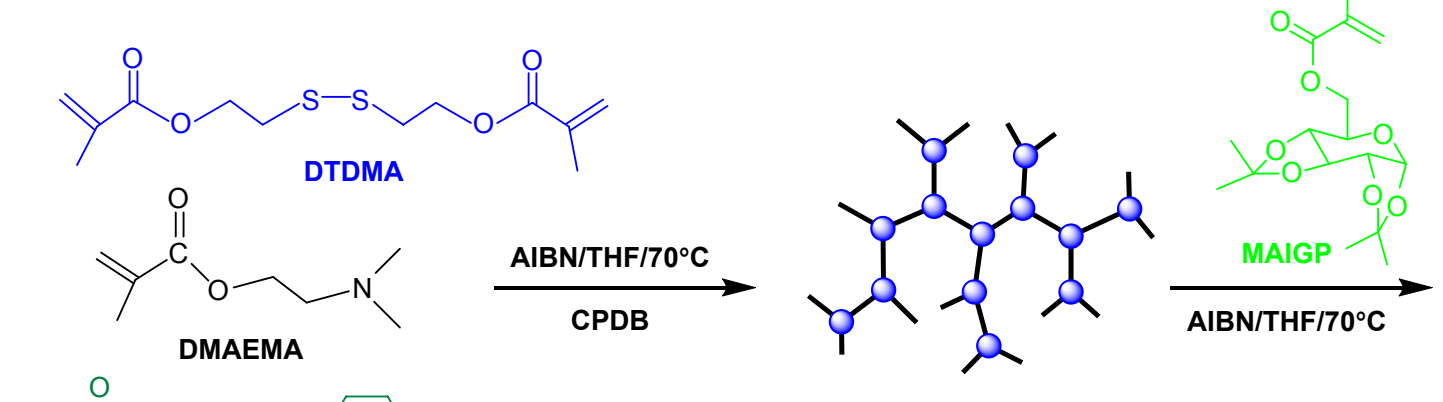<smiles>C=C(C)C(=O)OCCOc1ccc(C=O)cc1</smiles>

HP(DMAEMA-Co-MAEBA-co-DTDMA)

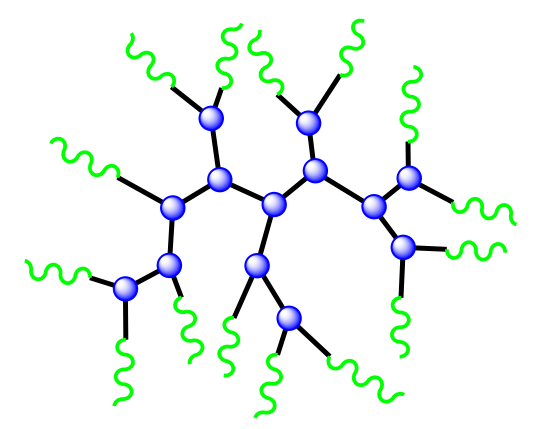

HP(DMAEMA-Co-MAEBA-Co-DTDMA)(PMAIGP)

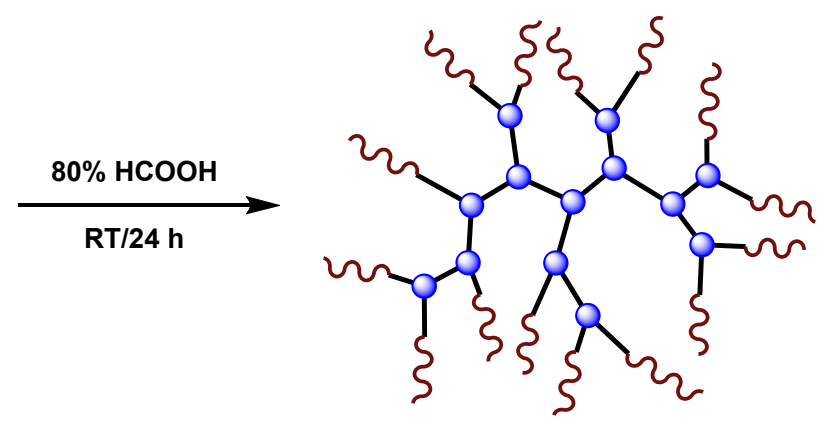

HP(DMAEMA-CO-MAEBA-Co-DTDMA)(PMAGP)<smiles>CC(C)(C)OCSSCCOC(=O)C(C)(C)C</smiles><smiles>CN(C)CCOC(=O)OCCOc1ccc(C=O)cc1</smiles>

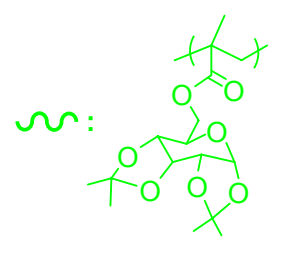

PMAIGP

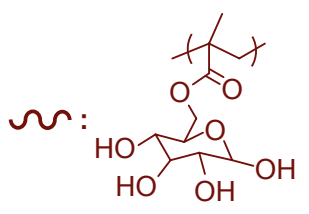

PMAGP

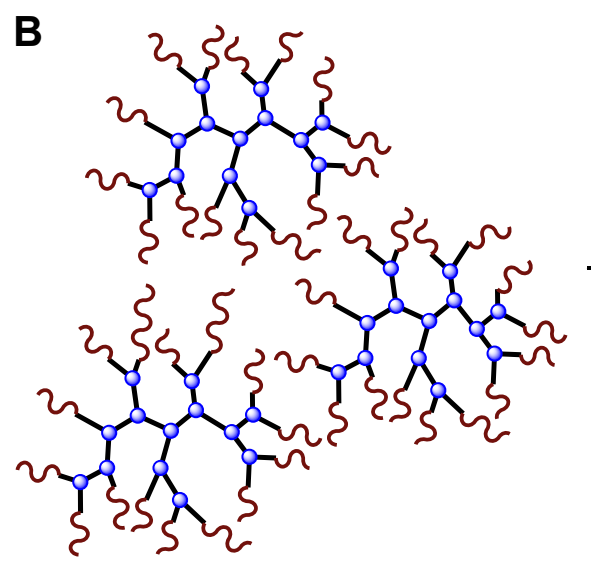

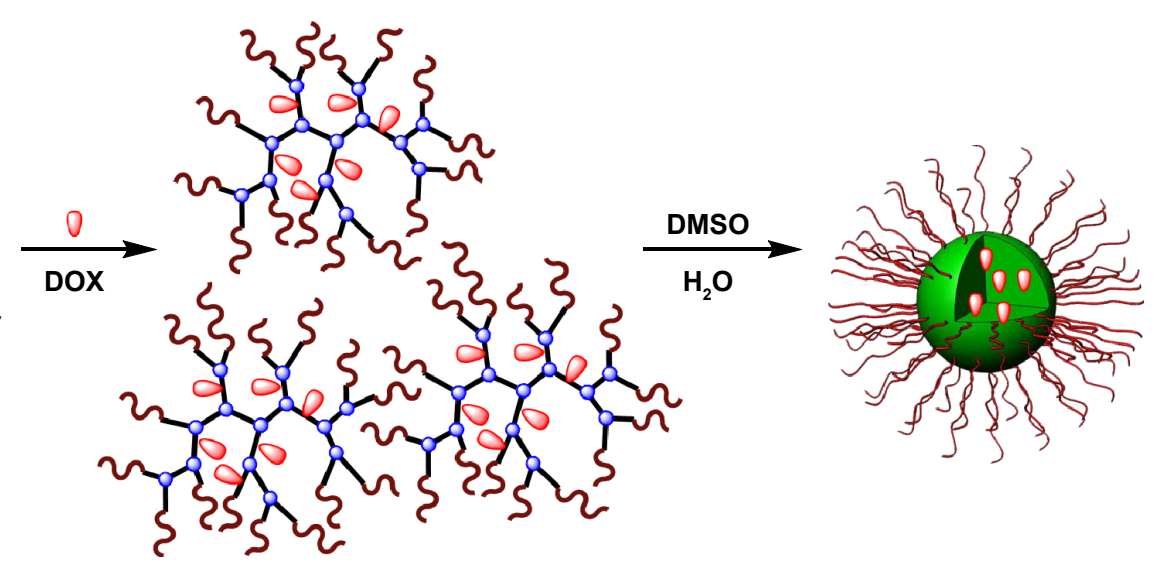

Figure I Synthesis of BP(DMAEMA-co-MAEBA-co-DTDMA)(PMAGP) $)_{n}(\mathbf{A})$; loading of DOX and formation of DOX-loaded BP(DMAEMA-co-MAEBA-co-DTDMA) (PMAGP) $)_{\mathrm{n}}$ micelles (B).

Abbreviations: BP, branched polymer; AIBN, Azobis(isobutyronitrile); BP(DMAEMA-co-MAEBA-co-DTDMA)(PMAGP), branched poly(2-[N,N-dimethylaminoethyl] methacylate-co-p-[methacryloxyethoxy] benzadehyde-co-2,2'-dithiodiethoxyl dimethacrylaye)(poly["6-O-Methacrylol-D-galactopyranose]); ; THF, tetrahydrofuran; DMAEMA, 2-(N,N-dimethylaminoethyl)methacrylate; MAEBA, p-(methacryloxyethoxy)benzaldehyde; DTDMA, 2,2'-dithiodiethoxyl dimethacrylate; PMAGP, poly(6-O-methacryloylD-galactopyranose); CPDB, cyanoisopropyl dithiobenzoate; DOX, doxorubicin; DMSO, dimethyl sulfoxide; h, hours; PMAIGP, poly(6-O-methacryloyl-I,2;3,4,-di-Oisopropylidene-D-galactopyranose); MAEBA, p-(methacryloxyethoxy)benzaldehyde; RT, room temperature. 
5.57 and $6.12\left(\mathrm{~s}, 2 \mathrm{H},=\mathrm{CH}_{2}\right) ; 7.00$ and $7.81\left(\mathrm{~d}, 4 \mathrm{H},-\mathrm{C}_{6} \mathrm{H}_{4}\right)$; and $9.86(\mathrm{~s}, 1 \mathrm{H},-\mathrm{CHO}) .2,2^{\prime}$-Dithiodiethoxyl dimethacrylate (DTDMA) was synthesized according to the literature, ${ }^{13}$ and its ${ }^{1} \mathrm{H}-\mathrm{NMR}\left(300 \mathrm{MHz}, \mathrm{CDCl}_{3}\right.$, $\delta$, ppm) was as follows: $1.88\left(\mathrm{~s}, 6 \mathrm{H},-\mathrm{CH}_{3}\right) ; 2.88-2.93$ $\left(\mathrm{t}, 4 \mathrm{H},-\mathrm{S}-\mathrm{CH}_{2}-\right)$; 4.31-4.36 (t, $\left.4 \mathrm{H},-\mathrm{O}^{-} \mathrm{CH}_{2}-\right)$; and 5.52 and $6.07\left(\mathrm{~s}, 4 \mathrm{H},=\mathrm{CH}_{2}\right) .2-(\mathrm{N}, \mathrm{N}-$ Dimethylaminoethyl) methacrylate (DMAEMA, 97\%, Alfa) was purified by passing it through a basic alumina column; then, it was vacuum-distilled and was stored at $-18^{\circ} \mathrm{C}$ prior to use. Tetrahydrofuran (THF) was refluxed over sodium for 24 hours and distilled prior to use. Azobis(isobutyronitrile) (AIBN; Sigma-Aldrich Co, St Louis, MO, USA) was recrystallized from ethanol. Cyanoisopropyl dithiobenzoate (CPDB) was prepared according to our previous report. ${ }^{13}$ Doxorubicin hydrochloride (DOX.HCl) and 2-(4amidinophenyl)-6-indolecarbamidine dihydrochloride (DAPI) were respectively purchased from Aladdin (Alladin Industrial Corporation, Shanghai, People's Republic of China) and Sigma-Aldrich Co, respectively; both were used as received. All other reagents with analytical grade were purchased from Shanghai Chemical Reagent Co (Shanghai, People's Republic of China) and were used as received.

\section{Characterization}

${ }^{1} \mathrm{H}-\mathrm{NMR}$ measurements were carried out on a Bruker AV300 NMR spectrometer (Bruker Corporation, Billerica, MA, USA) using $\mathrm{CDCl}_{3}$ or $\mathrm{D}_{2} \mathrm{O}$ or dimethyl sulfoxide (DMSO)- $\mathrm{d}_{6}$ as solvent. Molecular weight $\left(M_{\mathrm{w}}\right)$ and molecular weight distribution $\left(M_{\mathrm{w}} / M_{\mathrm{n}}\right)$ were determined on a Waters Corporation (Milford, MA, USA) $150 \mathrm{C}$ gel permeation chromatography (GPC) instrument equipped with microstyragel columns $\left(500,10^{3}\right.$, and $\left.10^{4} \AA\right)$ and an RI 2414 detector set at $30^{\circ} \mathrm{C}$; monodispersed polystyrene standards were used in the calibration of the number-average molecular weight $\left(M_{\mathrm{n}}\right), M_{\mathrm{w}}$, and $M_{\mathrm{w}} / M_{\mathrm{n}}$, and THF was used as an eluent at a flow rate of $1.0 \mathrm{~mL} / \mathrm{min}$. Ultraviolet (UV)/visible (Vis) light measurement was performed on a Unico (United Products \& Instruments, Inc., NJ, USA) UV/Vis 2802PCS spectrophotometer. Transmission electron microscopy (TEM) observations were conducted on a JEM-100SX electron microscope at an acceleration voltage of $100 \mathrm{kV}$. The sample for TEM observation was prepared by placing $10 \mu \mathrm{L}$ of micellar solution on a copper grid coated with thin films of Formvar and carbon. Dynamic light scattering (DLS) measurements were carried out on a DynaPro light scattering instrument (model DynaPro-99E) at $25^{\circ} \mathrm{C}$ with an $824.3 \mathrm{~nm}$ laser, and the data were analyzed with DYNAMICS V6 software.

\section{Synthesis of branched polymers BP(DMAEMA-co-MAEBA-co- DTDMA)s}

A typical polymerization procedure is as follows. Into a $5 \mathrm{~mL}$ polymerization tube, DMAEMA (678 $\mathrm{mg}, 4.32 \mathrm{mmol}$ ), DTDMA (52 mg, $0.18 \mathrm{mmol}$ ), MAEBA (113 mg, $0.48 \mathrm{mmol}$ ), CPDB (26.5 mg, $0.12 \mathrm{mmol}$ ), AIBN (4.9 mg, $0.03 \mathrm{mmol}$ ) and THF $(2.5 \mathrm{~mL})$ were successively added. The mixture was degassed through three freeze-pump-thaw cycles. The polymerization tube was then flame-sealed under vacuum, and the sealed tube was immersed in an oil bath at $70^{\circ} \mathrm{C}$. After 24 hours, the polymerization tube was cooled to room temperature rapidly, and the polymer was obtained by precipitation from n-hexane. The obtained product was dried overnight in a vacuum oven at room temperature.

\section{Synthesis of BP(DMAEMA-co- MAEBA-co-DTDMA)(PMAIGP)}

A typical polymerization procedure was followed. Into a 2 mL polymerization tube, BP(DMAEMA-co-MAEBAco-DTDMA)-1 (BP-1) $\left(M_{\mathrm{n}}=8,000 \mathrm{~g} / \mathrm{mol}, 32 \mathrm{mg}, 4 \mu \mathrm{mol}\right)$, MAIGP (262 mg, $0.8 \mathrm{mmol})$, AIBN $(0.1336 \mathrm{mg}, 0.8 \mu \mathrm{mol})$, and THF $(2 \mathrm{~mL})$ were added. After three freeze-vacuum-thaw cycles, the polymerization tube was sealed under vacuum. The polymerization was carried out at $70^{\circ} \mathrm{C}$ for a prescribed time. The polymerization tube was cooled to room temperature rapidly, and then the reaction mixture was precipitated into an excess of $\mathrm{n}$-hexane. The obtained product was dried overnight in a vacuum oven at room temperature.

\section{Hydrolysis of BP(DMAEMA-co- MAEBA-Co-DTDMA)(PMAIGP)}

The BP(DMAEMA-co-MAEBA-co-DTDMA)(PMAIGP) $(200 \mathrm{mg})$ was stirred in $80 \%$ formic acid $(10 \mathrm{~mL})$ for 48 hours at room temperature; then, deionized water $(3 \mathrm{~mL})$ was added, and the mixture was stirred for an additional 3 hours. The final solution was dialyzed against deionized water for 3 days to remove the formic acid. The product was obtained as a white cotton-like solid by lyophilization.

\section{Fabrication of BP(DMAEMA-co- MAEBA-co-DTDMA)(PMAGP), micelles}

BP(DMAEMA-co-MAEBA-co-DTDMA)(PMAGP) $(20 \mathrm{mg}$ ) was dissolved in DMSO $(2 \mathrm{~mL})$. Under vigorous stirring, deionized water $(8 \mathrm{~mL})$ was slowly added. The dispersion was stirred for another 3 hours; then, DMSO was 
removed by dialysis $\left(M_{\mathrm{w}}\right.$ cutoff 3,500 Da) against deionized water for 48 hours.

\section{Preparation of DOX-loaded micelles}

BP(DMAEMA-co-MAEBA-co-DTDMA)(PMAGP) (30 mg) was dissolved in $5 \mathrm{~mL}$ of DMSO at room temperature, and then $\mathrm{DOX} \cdot \mathrm{HCl}(30 \mathrm{mg})$ and an equal molar amount of triethylamine were added. The mixture was stirred for 3 hours and subsequently was slowly added into $10 \mathrm{~mL}$ of phosphate-buffered saline (PBS; $50 \mathrm{mM}, \mathrm{pH}$ 7.4). After having been stirred for another 2 hours, the resultant solution was dialyzed against deionized water for 18 hours ( $M_{\mathrm{w}}$ cutoff 3,500 Da) at room temperature, and the deionized water was changed every 2 hours. The contents inside the dialysis bag were filtered and lyophilized. The amount of DOX was determined by UV/Vis quantitative analysis (excitation at $497 \mathrm{~nm}$ ), and the standard curve was obtained by plotting the UV absorbance at $497 \mathrm{~nm}$ with different concentrations of DOX in DMSO solutions. To determine the total loading of the drug, the DOX-loaded micelles were dissolved in DMSO, and the concentration of DOX in DMSO was determined based on the UV absorbance at $497 \mathrm{~nm}$. Drug loading content (DLC) and grafting efficiency (GE) of DOX were calculated according to Equations 1 and 2, respectively:

$$
\begin{aligned}
& \text { DLC }(w t \%)=\frac{\text { Weight of loaded drug }}{\text { Weight of polymer }} \times 100 \% \\
& \text { GE }(w t \%)=\frac{\text { Weight of loaded DOX }}{\text { Weight of DOX added }} \times 100 \%
\end{aligned}
$$

\section{Degradation of BP(DMAEMA-co- MAEBA-co-DTDMA)(PMAGP)}

BP(DMAEMA-co-MAEBA-co-DTDMA)(PMAGP) (20 mg) was dissolved in $10 \mathrm{~mL}$ of the deionized water at room temperature; subsequently, $10 \mathrm{mM}$ dithiothreitol (DTT) was added. The mixture was stirred for 48 hours. After reaction, the product was dealt with using dialysis $\left(M_{\mathrm{w}}\right.$ cutoff $3,500 \mathrm{Da}$ ) against deionized water for another 48 hours, and then the product was dried by freeze drying.

\section{In vitro release measurements}

The drug release was performed under both reduction-insensitive and reduction-sensitive conditions. For the reduction-sensitive experiment, the drug release was performed under various $\mathrm{pH}$ values $(\mathrm{pH}$ values of 5, 6, and 7.4). A typical procedure in the current study was as follows: an aqueous dispersion of DOX-loaded micelles $(2.0 \mathrm{mg} / \mathrm{mL}$,
$3.0 \mathrm{~mL}$ ) was transferred to a dialysis bag with a $M_{\mathrm{w}}$ cutoff of $3.5 \mathrm{kDa}$, and then the dialysis bag was immersed in $60 \mathrm{~mL}$ of various buffer solutions (with $\mathrm{pH}$ values of 5, 6, and 7.4) containing $10 \mathrm{mM}$ DTT $(90 \mathrm{mg})$, which was purged with pure nitrogen for 30 minutes prior to use. The samples (2 $\mathrm{mL}$ ) were taken at predetermined time intervals for estimating the amount of drug released, and the same method was employed for the reduction-insensitive experiment, except for the use of pure PBS solution to replace the buffer solution. UV absorbance of the dialysis solution at $497 \mathrm{~nm}$ was monitored to determine the DOX releasing profile. A series of parallel experiments was conducted. Each measurement was done in triplicate, and the data are shown as the mean value plus a standard deviation $( \pm \mathrm{SD})$.

\section{Cellular uptake}

Cellular uptake behaviors of DOX-loaded micelles (BSP-3DOX) by HepG2 or HeLa cells were examined by confocal laser scanning microscopy (CLSM; Leica TCP SP5 [Leica Microsystems, Wetzlar, Germany]). HepG2 and HeLa cells were cultured in Dulbecco's Modified Eagle's Medium (DMEM) supplemented with 10\% fetal bovine serum (FBS) for 24 hours at $37^{\circ} \mathrm{C}$ under an atmosphere with $5 \% \mathrm{CO}_{2}$ in a 96-well plate, then changed to freshly prepared DMEM which contains $15.9 \mu \mathrm{g} / \mathrm{mL}$ of pure DOX $(100 \mu \mathrm{g} / \mathrm{mL}$ of the BSP-3-DOX contains $15.9 \mu \mathrm{g} / \mathrm{mL}$ of the pure DOX), which are respectively equivalent to DOX concentrations of $15.9 \mu \mathrm{g} / \mathrm{mL}$. After being treated for 4 hours, the culture medium was removed; the cells, after being rinsed two times with PBS, were fixed with formaldehyde, and the cell nuclei were stained with DAPI (4',6-diamidino-2-phenylindole) (blue stain). The cells were rinsed with PBS buffer, and were observed using a CLSM (Leica TCP SP5) at $595 \mathrm{~nm}$ (excitation wavelength $\left[E_{\mathrm{x}}\right]=485 \mathrm{~nm}$ ).

\section{In vitro cytotoxicity evaluation}

The cell viability of HepG 2 cells or HeLa cells incubated with DOX $\cdot \mathrm{HCl}, \mathrm{BSP}-3$ micelles and DOX-loaded micelles (BSP3-DOX) was tested using the standard thiazolyl blue MTT assay. HepG2 cell or HeLa cells were cultured in DMEM supplemented with $10 \% \mathrm{FBS}$ at $37^{\circ} \mathrm{C}$ under an atmosphere with $5 \% \mathrm{CO}_{2}$. The cells were seeded in 96-well plates at a density of 5,000 cells per well for 24 hours before treatment. The cells were treated with various concentrations of DOX $\cdot \mathrm{HCl}, \mathrm{BSP}-3$ and BSP-3-DOX for 24 hours in 96-well plates. The culture medium in each well was removed and replaced by $100 \mu \mathrm{L}$ of DMSO. The plate was gently agitated for 15 minutes, and the absorbance values were recorded at a wavelength of $490 \mathrm{~nm}$ using a Thermo Electron MK3 
spectrophotometer (Thermo Fisher Scientific, Waltham, MA, USA). Cell viability was calculated as

$$
\frac{\mathrm{A}_{490 \text {, treated }}}{\mathrm{A}_{490, \text { control }}} \times 100 \% \text {, }
$$

where $\mathrm{A}_{490 \text {,treated }}$ and $\mathrm{A}_{490, \text { control }}$ are the absorbance values with or without the addition of micelles, respectively. Each experiment was done in triplicate. The data are shown as the mean value plus $\pm \mathrm{SD}$. Cell viability was thereby determined.

\section{Results and discussion Synthesis of BP(DMAEMA-co-MAEBA- co-DTDMA)(PMAGP)}

Similar to the synthesis strategy used to produce the dendrimer-star copolymers in our previous reports, ${ }^{47,48}$ the first step in the current report was synthesis of the branched copolymers, which were prepared by RAFT copolymerization of DMAEMA, MAEBA, and DTDMA, using CPDB as the RAFT agent, as shown in Figure 1A. The DTDMA is a divinyl monomer and was therefore used as divergent agent. It is well known that controlled radical copolymerization of the divinyl and monovinyl monomers in an appropriate recipe produces branched copolymers, and degree of branching (DB) is determined by the ratio of divinyl monomer/monovinyl monomer. ${ }^{49,50}$ The feed molar ratio of [DMAEMA+MAEBA]/ [CPDB]/[DTDMA] was fixed at 40/1/1.5, but the feed molar ratio of [DMAEMA]/[MAEBA] was varied for achieving various contents of the aldehyde groups, and the detailed polymerization conditions and results are listed in Table 1. Similar to the branched copolymerization with divinyl monomer as a divergent agent in a previous report, ${ }^{49}$ high yields $(\sim 99 \%)$ of the resultant branched copolymers were obtained (Table 1). Their $M_{\mathrm{w}}$ and $M_{\mathrm{w}} / M_{\mathrm{n}}$ were characterized by GPC, all the GPC traces in Figure S1 display bimodally, and their $M_{\mathrm{w}} / M_{\mathrm{n}}$ are broad, which is consistent with controlled radical copolymerization of the mono- and divinyl monomers, because the branched polymers are formed via step polymerization of the linear polymer chains. ${ }^{49,50}$

To understand branched structure and compositions of the obtained polymers, their ${ }^{1} \mathrm{H}-\mathrm{NMR}$ spectra were measured, and a typical ${ }^{1} \mathrm{H}-\mathrm{NMR}$ spectrum of the branched copolymer, BP-3, is shown in Figure 2A. The DMAEMA, MAEBA, and DTDMA units in the branched copolymer are supported by their characteristic proton signals: the proton signals of the aldehyde and aromatic groups in the MAEBA units are at $\delta=9.86$ (a), $\delta=7.82$ (b), and $\delta=6.99 \mathrm{ppm}$ (c); the proton signals of methyl and methylene are next to nitrogen, as well as ester methylene in DMAEMA units at $\delta=2.25(\mathrm{~g})$, $\delta=2.53$ (f), and $\delta=4.04 \mathrm{ppm}$ (e); and the proton signals of methylene are next to sulfur and ester methylene in DTDMA units at $\delta=2.5 \sim 3.5$ (1) and $\delta=4.24 \mathrm{ppm}$ (d), respectively. Compositions of the resultant branched copolymers were calculated based on integral values of the signals at $\delta=9.86$ (a), $\delta=2.57 \mathrm{ppm}$ (f), and $\delta=2.5 \sim 3.5 \mathrm{ppm}$ (1); the results are listed in Table 1. We can see that the molar ratios of [DMAEMA]:[MAEBA] in the polymers are higher than that in the feed, indicating lower reactivity of MAEBA in comparison with DMAEMA, probably owing to bulky side group of the MAEBA monomer. The ${ }^{13} \mathrm{C}-\mathrm{NMR}$ spectrum of BP-3 also supports the idea that the branched polymers are composed of DMAEMA, MAEBA, and DTDMA units: the characteristic carbon signal of methyl carbon is next to nitrogen in the DMAEMA unit at $\delta=45.5 \mathrm{ppm}(\mathrm{m})$; the characteristic aldehyde carbon signal of the MAEBA unit is at $\delta=190.7 \mathrm{ppm}$ (a); and the carbon signal of methylene is next to sulfur in the DTDMA unit at $\delta=34 \mathrm{ppm}$.

Since the branching point is formed only when the pendent vinyl groups of the divinyl monomer units in the polymer chains participate in reaction, ${ }^{49}$ no vinyl proton signals are observed in the range of 5-6.7 ppm in Figure 2A, indicating that all DTDMA units in the polymer chains become branching units. Therefore, the content of divinyl monomer, in which

Table I Synthetic conditions and results of BP(DMAEMA-co-MAEBA-co-DTDMA)

\begin{tabular}{lllllll}
\hline No & $\begin{array}{l}\text { Feed molar ratio of } \\
\text { D:B:T:C:AIBN }\end{array}$ & $\begin{array}{l}\text { Yield } \\
(\%)^{b}\end{array}$ & $\begin{array}{l}M_{n}(G P C) \\
(\mathbf{g} / \mathbf{m o l})^{\mathbf{c}}\end{array}$ & $M_{w} I_{n}^{c}$ & $\begin{array}{l}\text { DP of primary } \\
\text { chain }^{\mathbf{d}}\end{array}$ & $\begin{array}{l}\text { Molar ratio of } \\
\text { [D]:[B]:[T] in polymer }\end{array}$ \\
\hline BP-I & $36: 4: 1.5: 1: 0.25$ & 99 & 8,000 & 1.99 & 37 & $10: 1: 0.9$ \\
BP-2 & $32: 8: 1.5: 1: 0.25$ & 99 & 7,600 & 2.04 & 43 & $5: 1: 0.49$ \\
BP-3 & $16: 24: 1.5: 1: 0.25$ & 99 & 13,100 & 1.98 & 36 & $0.8: 1: 0.15$ \\
\hline
\end{tabular}

Notes: ${ }^{\mathrm{a}} \mathrm{D}, \mathrm{B}, \mathrm{T}$, and $\mathrm{C}$ refer to DMAEMA, MAEBA, DTDMA, and CPDB, respectively. Polymerization temperature was $70^{\circ} \mathrm{C}$; time was 24 hours. ${ }^{\mathrm{b}} \mathrm{Determined}$ by gravimetry. 'Determined by GPC, calibrated based on the narrow polystyrene standards. ${ }^{\mathrm{d}}$ Calculated according to $\mathrm{DP}=(19.86+12.57 / 2+12.5-3.5 / 4) /(17.52 / 2)$. ${ }^{\mathrm{C}} \mathrm{Molar}$ ratios of [DMAEMA]:[MAEBA]:[DTDMA] in the polymers were calculated according to 'H-NMR data.

Abbreviations: BP(DMAEMA-co-MAEBA-co-DTDMA), branched poly(2-[N,N-dimethylaminoethyl]methacylate-co-p-[methacryloxyethoxy]benzadehyde-co-2,2'-dithiodiethoxyl dimethacrylaye); BP, branched polymer; $M_{w} / M_{n}$, molecular weight distribution; DMAEMA, 2-(N,N-dimethylaminoethyl)methacrylate; MAEBA, p-(methacryloxyethoxy)benzaldehyde; DTDMA, 2,2'-dithiodiethoxyl dimethacrylate; CPDP, cyanoisopropyl dithiobenzoate; GPC, gel permeation chromatography; 'H-NMR, hydrogen-I nuclear magnetic resonance; AIBN, Azobis(isobutyronitrile); $M_{w}$, weight-average molecular weight; $M_{n}$, number-average molecular weight; DP, number-average degree of polymerization. 


\section{A}

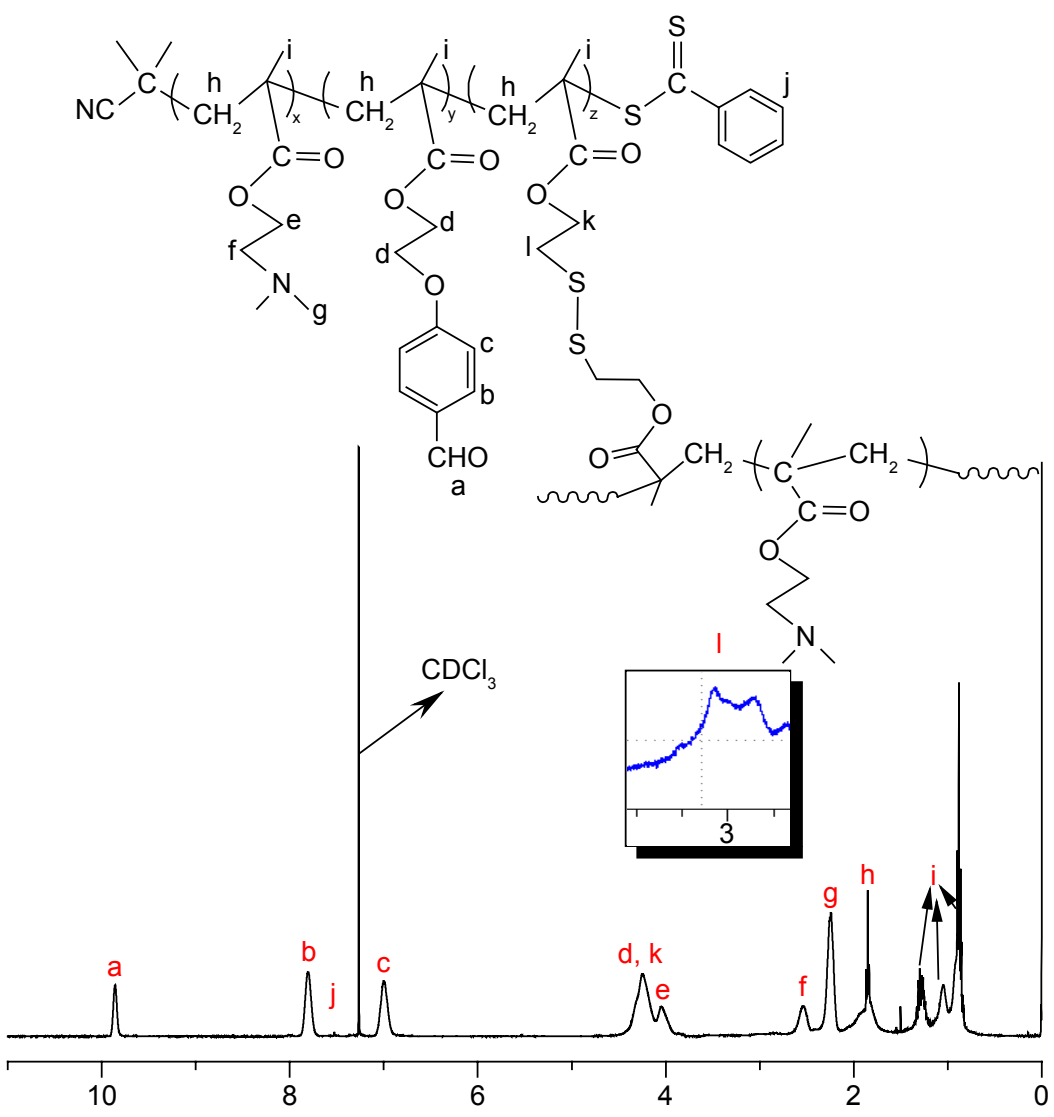

B

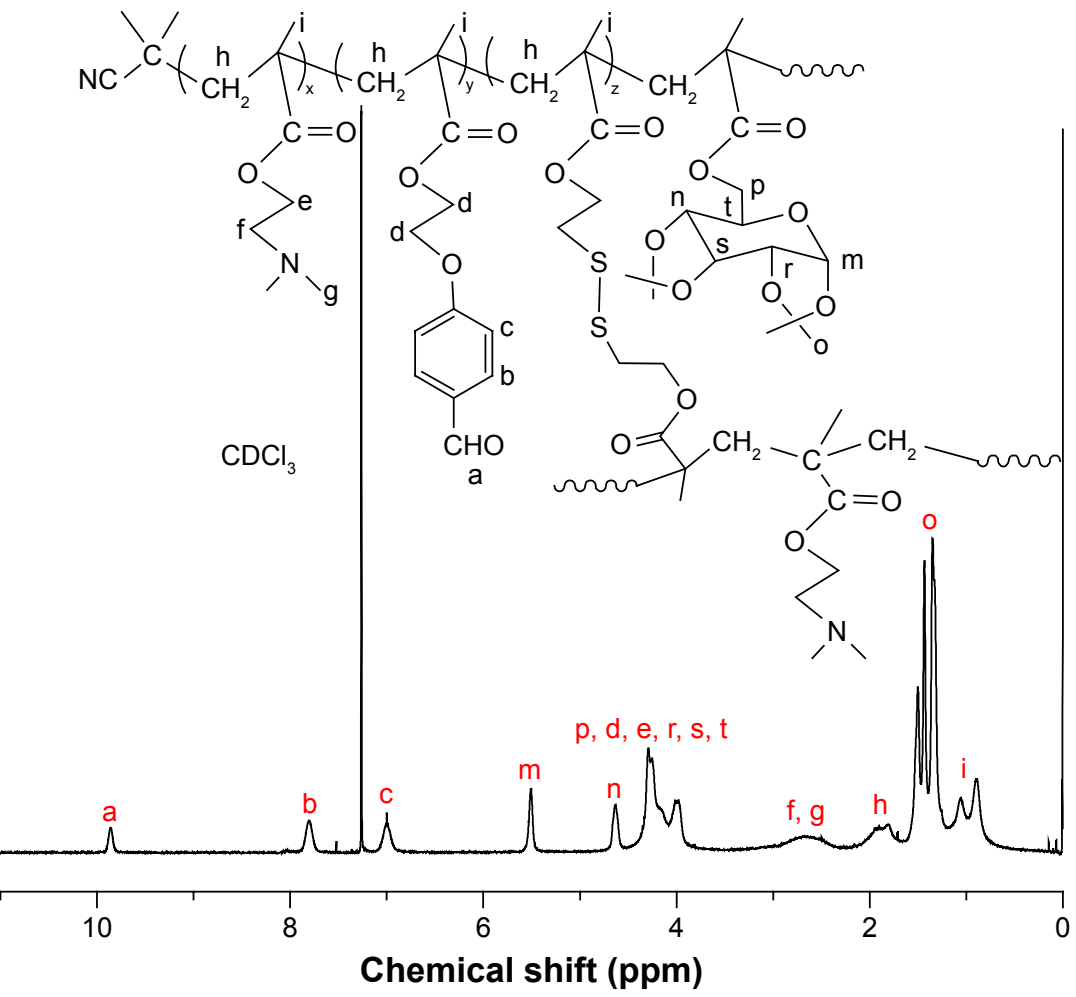

Figure 2 'H-NMR spectra of the branched polymer, BP(DMAEMA-co-MAEBA-co-DTDMA), BP-3 (A), and the branched star polymer, (DMAEMA-co-MAEBA-co-DTDMA) (PMALGP), BSP-3 (B).

Abbreviations: PMAIGP, poly(6-O-methacryloylproperty-I,2; 3,4-di-O-isopropylidene-D-galactopyranose); 'H-NMR, hydrogen-I nuclear magnetic resonance; BP, branched polymer; DTDMA, 2,2'-dithiodiethyoxly dimethacrylate; DMAEMA, 2-(N,N-dimethy laminoethyl)methacrylate; MAEBA, P-(methacryloxyethoxy)benzaldehyde. 
two vinyl groups are reacted, can be used to estimate DB; the contents of DTDMA are listed in Table 1. According to the formation mechanism of the branched copolymers proposed by Yang et $\mathrm{al}^{49}$ in the controlled radical polymerization of mono- and divinyl monomers, the primary chains are formed first, and then slightly branched polymers and highly branched polymers are successively produced by coupling reactions between two primary chains and then between two slightly branched polymers. Every primary chain is terminated by a dithiobenzoate group; their number-average degree of polymerization (DP) can be estimated based on ${ }^{1} \mathrm{H}-\mathrm{NMR}$ data. Figure $2 \mathrm{~A}$ reveals a proton signal at $\delta=7.52 \mathrm{ppm}(\mathrm{j})$, which is ascribed to the dithiobenzoate group. Based on the integral values of proton signals at $\delta=9.86$ (a), $\delta=2.57$ (f), $\delta=2.5 \sim 3.5$ (1), and $\delta=7.52 \mathrm{ppm}(\mathrm{j})$, the DP of the primary chain was calculated, and the results are listed in Table 1. The DP of primary chains is close to their feed molar ratio (41.5), probably due to high conversion of monomers. As we know, the BPs possess a number of dithiobenzoate groups on their surface; therefore, we used the branched polymers as a macro-RAFT agent in subsequent synthesis of the BSPs.

Galactose is a specific liver-targeting ligand, which can mediate delivery of drugs to liver parenchymal cells through its strong binding with ASGP-R on the surface of the HepG2 human hepatoma cells. ${ }^{51,52}$ Thus, PMAIGP was chosen as the periphery polymer of the branched star copolymers, BP(DMAEMA-co-MAEBA-co-DTDMA)(PMAIGP) . BP-1 to BP-3 were respectively applied as a macro-RAFT agents in the RAFT polymerization of MAIGP for the synthesis of the branched star copolymers. The details of polymerization conditions and the results are listed in Table 2. The $M_{\mathrm{w}}$ and $M_{\mathrm{w}} / M_{\mathrm{n}}$ values of the resultant BP(DMAEMA-co-MAEBAco-DTDMA)(PMAIGP) , were measured by GPC, and the results are listed in Table 2. GPC traces of BSP-1, BSP-2, and BSP-3 in Figure S2 reveal that they are shifted to the high $M_{\mathrm{w}}$ region, and that the $M_{\mathrm{w}} / M_{\mathrm{n}}$ values become narrower in comparison with the GPC curves of their corresponding precursors depicted in Figure S1, because RAFT polymerization of MAIGP produced the periphery PMAIGP chains with narrow $M_{\mathrm{w}} / M_{\mathrm{n}}$ values.

To estimate the compositions, and also to verify branched structure of the obtained polymers, their ${ }^{1} \mathrm{H}$ - and ${ }^{13} \mathrm{C}-\mathrm{NMR}$ spectra were measured; a typical ${ }^{1} \mathrm{H}-\mathrm{NMR}$ spectrum of BSP-3 is shown in Figure 2B. We can see the characteristic proton signals of MAIGP units: the anomeric proton signals appear respectively at $\delta=3.9-4.5$ (p, r, s, and t spectra peaks), $\delta=4.62[\mathrm{n}]$, and $\delta=5.52 \mathrm{ppm}[\mathrm{m}]$, and the signals at $\delta=1.25 \sim 1.60 \mathrm{ppm}$ (o) are attributed to the methyl proton of the isopropyl group. In addition, the characteristic proton signals of DMAEMA, MAEBA, and DTDMA units can be seen also; therefore, the expected BSPs have been successfully prepared. The ${ }^{13} \mathrm{C}$-NMR spectrum of BSP-3 in Figure 3B also supports the results obtained by ${ }^{1} \mathrm{H}-\mathrm{NMR}$ spectra; besides the characteristic carbon signals of DMAEMA, MAEBA, and DTDMA units, the characteristic carbon signals of MAIGP units appear at $\delta=108.2$ (n), 96.1 (o), and $71.4 \mathrm{ppm}(\mathrm{p})$; the carbon signals appearing at $\delta=25.96$ and 24.81 ppm (q) are ascribed to the two methyl carbons of the isopropyl groups. The molar ratios of MAIGP:MAEBA:DMAEMA in BSP-1, BSP-2, and BSP-3 were calculated based on the integral ratios of the signals at $\delta=5.50(\mathrm{~m}), 9.86(\mathrm{a})$, and $2.57 \mathrm{ppm}(\mathrm{f}, \mathrm{g})$, and the results are listed in Table 2.

For utilization of the polymers as a drug carrier, one requisite is that the polymers should be water soluble. However, the BSPs, BSP-1 to BSP-3, are hydrophobic; thus, the MAIGP units in the periphery of the BSPs should be hydrolyzed to form water-soluble PMAGP. The hydrolysis reaction of BP(DMAEMA-MAEBA-DTDMA)(PMAIGP) $)_{n}$ was conducted in $80 \%$ formic acid; the obtained polymer solution was dialyzed against deionized water and then lyophilized. The degree of hydrolysis was estimated by ${ }^{1} \mathrm{H}-\mathrm{NMR}$ spectrum of the reaction product. Figure 4 is a typical ${ }^{1} \mathrm{H}-\mathrm{NMR}$ spectrum of the BP(DMAEMA-MAEBA-DTDMA)(PMAGP) $n$ obtained from hydrolysis of BSP-3, and we can see that the isopropylidene proton signals at $\delta=1.2 \sim 1.6 \mathrm{ppm}$ almost completely disappear, indicating that the hydrolysis reaction was successful.

Table 2 Synthetic condition and results of BP(DMAEMA-co-MAEBA-co-DTDMA)(PMAIGP)

\begin{tabular}{|c|c|c|c|c|c|c|}
\hline $\mathbf{N o}^{a}$ & $\begin{array}{l}\text { Macro-RAFT } \\
\text { agent }\end{array}$ & $\begin{array}{l}\text { Feed molar ratio of } \\
{[\text { MAIGP]:[RAFT agent] }}\end{array}$ & $\begin{array}{l}\text { Yield } \\
(\%)^{\mathrm{b}}\end{array}$ & $\begin{array}{l}M_{n}(G P C) \\
(g / m o l)^{c}\end{array}$ & $M_{w} / M_{n}^{c}$ & $\begin{array}{l}\text { Molar ratio of } \\
{[D]:[B]:[M] \text { in polymer }}\end{array}$ \\
\hline BSP-I & BP-I & $100: 1$ & 60 & 20,500 & 1.63 & $10: 1: 24$ \\
\hline BSP-2 & BP-2 & $100: 1$ & 56 & 20,800 & 1.72 & $5: 1: 12$ \\
\hline BSP-3 & BP-3 & 100:I & 64 & 30,600 & 1.69 & $0.8: 1: 2.4$ \\
\hline
\end{tabular}

Notes: [D], [B], [M] refer to DMAEMA, MAEBA, and MAIGP, respectively. ${ }^{2}$ RAFT polymerization of MAIGP at $70^{\circ} \mathrm{C}$ for 24 hours respectively using BP-I, BP-2, and BP-3 as macro-RAFT agent. 'Determined by gravimetry method. 'Determined by GPC, $M_{n}$ and $M_{w} / M_{n}$ were calibrated based on the narrow polystyrene standards. ${ }^{d}$ Molar ratios of [DMAEMA]:[MAEBA]:[MAIGP] were calculated based on 'H-NMR data.

Abbreviations: BP(DMAEMA-co-MAEBA-co-DTDMA)(PMAIGP), branched poly(2-(N,N-dimethylaminoethyl)methacrylate-co-p-(methacryloylethoxy)benzaldehyde-co2,2'-dithiodiethoxyl dimethacrylate)(poly(6-O-methacryloyl-I,2; 3,4-di-O-isopropylidene-D-galactopyranose); BP, branched polymer; BSP, branched star polymer; No, number; RAFT, reversible addition-fragmentation chain transfer; PMAIGP, poly(6-O-methacryloylproperty-I,2; 3,4-di-O-isopropylidene-D-galactopyranose); $M_{n}$, numberaverage molecular weight; GPC, gel permeation chromatography; $M_{w}$, weight-average molecular weight; 'H-NMR, hydrogen-I nuclear magnetic resonance. 

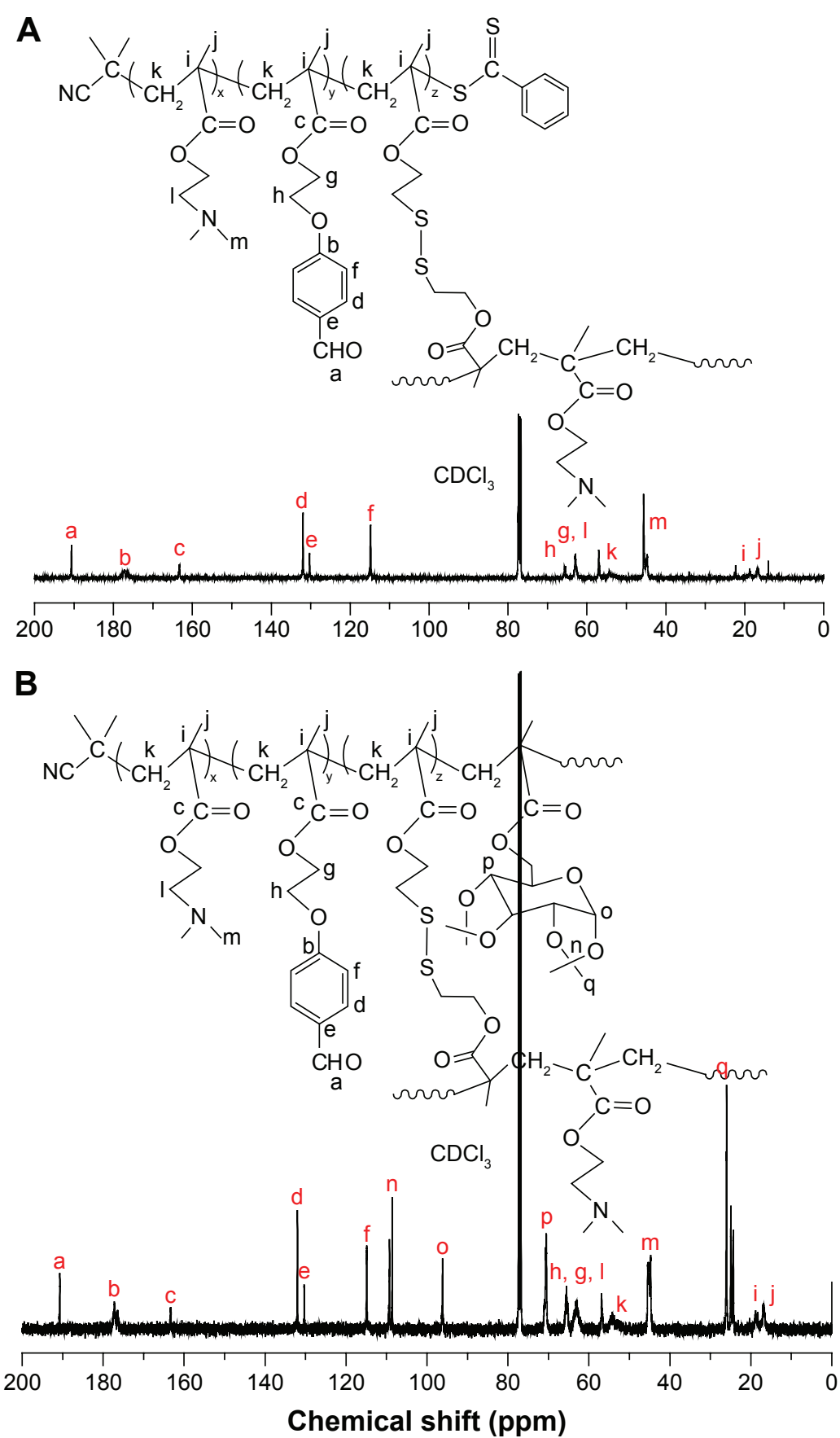

Figure $3{ }^{13} \mathrm{C}-\mathrm{NMR}$ spectra of the branched polymer, BP-3 (A), and the branched star polymer, BSP-3 (B).

Abbreviation: ${ }^{13} \mathrm{C}-\mathrm{NMR}$, carbon- 13 nuclear magnetic resonance.

Owing to amphiphilic properties of the hydrolyzed products, BP(DMAEMA-co-MAEBA-co-DTDMA)(PMAGP) $)_{\mathrm{n}}$, they are soluble in water to form spherical micelles, theoretically. TEM and DLS were used to characterize the assemblies, and the results are shown in Figures $\mathrm{S} 3$ and 5A. The TEM images in Figure S3 reveal that self-assembly of the three branched star copolymers, BSP-H1, BSP-H2, and BSP-H3, forms spherical micelles in water; their numberaverage diameters $\left(\mathrm{D}_{\mathrm{TEM}} \mathrm{s}\right)$ are $30-40 \mathrm{~nm}$, and the size distributions are broad (Table 3). Compared to the $\mathrm{D}_{\text {TEM }} \mathrm{S}$, the diameters obtained by DLS method are relatively big (Table 3), which is reasonable because the sizes obtained from TEM are in the dry state, whereas the size measured by DLS is in the swollen state.

\section{Covalent linkage of DOX onto BSP-Hs and micellization}

The condensation reaction between primary amines and aldehydes is well-known in organic chemistry, and has been used in drug preparation. ${ }^{39,53}$ Thus, the anti-cancer drug DOX 


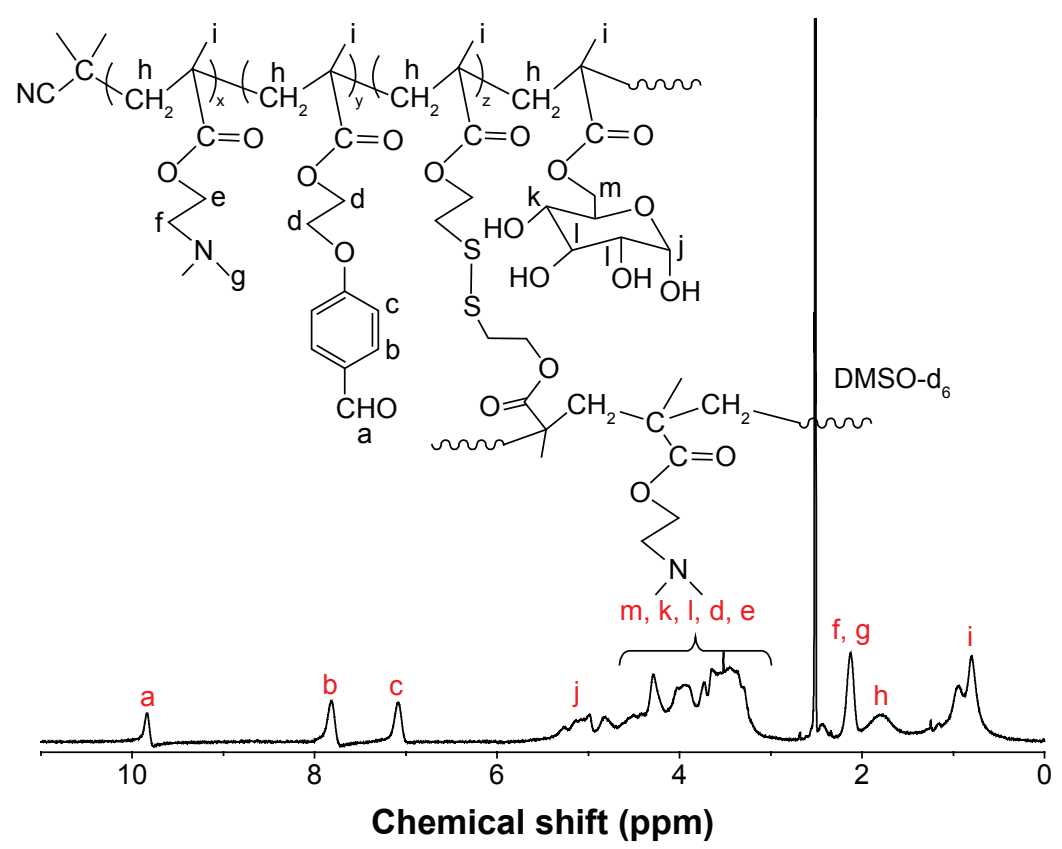

Figure 4 'H-NMR spectrum of the BP(DMAEMA-co-MAEBA-co-DTDMA)3(PMAGP) in DMSO.

Abbreviations: 'H-NMR, hydrogen-I nuclear magnetic resonance; BP, branched polymer; DTDMA, 2,2'-dithiodiethyoxly dimethacrylate; DMAEMA, 2-(N,Ndimethylaminoethyl)methacrylate; MAEBA, p-(methacryloxyethoxy)benzaldehyde; PMAGP, poly(galactosyl methacrylate); DMSO, dimethyl sulfoxide.

was covalently linked to BSP-Hs by the reaction of primary amine in DOX with the aldehyde of MAEBA units, forming the DOX-loaded BSP-Hs via acid-labile imine linkage. To identify whether this reaction occurred, the ${ }^{1} \mathrm{H}-\mathrm{NMR}$ spectra of the reaction products were measured, and a typical ${ }^{1} \mathrm{H}-\mathrm{NMR}$ spectrum of BP(DMAEMA-co-MAEBAco-DTDMA)(PMAGP) $)_{\mathrm{n}}$ DOX is shown in Figure 5A; in addition to the characteristic proton signals of DMAEMA, MAEBA, DTDMA, and MAGP units, we can see aromatic proton signals of DOX at $\delta=7.20-7.72 \mathrm{ppm}$. Therefore, the covalent linking of DOX onto the core polymer chains was successful.

Based on the weight increase of the sample and the weight of DOX added, the GEs of DOX were calculated, and the results are listed in Table 4. Since the proton signals of DOX and MAEBA overlap, the content of DOX is difficult to accurately calculate from ${ }^{1} \mathrm{H}-\mathrm{NMR}$ data; UV quantitative analysis was used to measure their DLCs, as well as DOX contents, based on the absorption strength alteration at $497 \mathrm{~nm},{ }^{24,54}$ and the results are listed in Table 4. Based on the molar ratio of DMAEMA:MAEBA:DTDMA:MAGP, theoretical DLC values were calculated; they are $7.3 \mathrm{wt} \%, 13.1 \mathrm{wt} \%$ and $37.6 \mathrm{wt} \%$ for BSP-H1, BSP-H2, and BSP-H3, respectively. The measured DLCs are much lower than the corresponding theoretical values. The low GEs and DLCs are ascribed to low reaction efficiency (around 30\%) of the primary amine and the aldehyde in the core of BSP-H micelles, due to the bulk of DOX.
As discussed, the hydrolyzed products of BSPs, BSP-H1, $\mathrm{BSP}-\mathrm{H} 2$, and BSP-H3, are dissolved in water, forming spherical micelles. After covalently linking DOX onto the core polymer chains of the BSP-Hs, the DOX-loaded products, BSP-H-DOXs, are also dissolved in water, and the spherical micelles with BP(DMAEMA-MAEBA-DOX-DTDMA) as core and PMAGP as shell are formed, as shown in Figure 1B. To confirm the formation of core-shell micelles, ${ }^{1} \mathrm{H}-\mathrm{NMR}$ spectra, TEM, and DLS were used to characterize the assemblies formed. Figure 6A and B are DLS curves of the BSP-Hs and BSP-H-DOXs, respectively, and their size and size distributions are listed in Table 4. Compared to Figure 6A, the diameters of DOX-loaded BSP-Hs (90, 170, and $120 \mathrm{~nm}$ ) are larger than that of their corresponding precursors $(50,40$, and $55 \mathrm{~nm}$ ). The reason is that covalently linking DOX onto the core polymer chains increases the hydrophobic property of the core, which is consistent with the result observed in selfassembling of asymmetric block copolymers to form crew-cut aggregates. ${ }^{55}$ Figures S3 and S4 are the TEM images of BSP-Hs and BSP-H-DOXs. Comparing the micelle's size in Figure S3 with that in Figure S4, both are spherical micelles.

Since divergent agent DTDMA contains disulfide linkage the BSPs prepared from DTDMA are of redox-responsive property, such as glutathione and DTT, can degrade disulfidecontaining polymers, ${ }^{56}$ and these types of redox-sensitive polymers have been extensively used in drug delivery systems. ${ }^{57,58}$ Thus, BP(DMAEMA-co-MAEBA-co-DTDMA) 

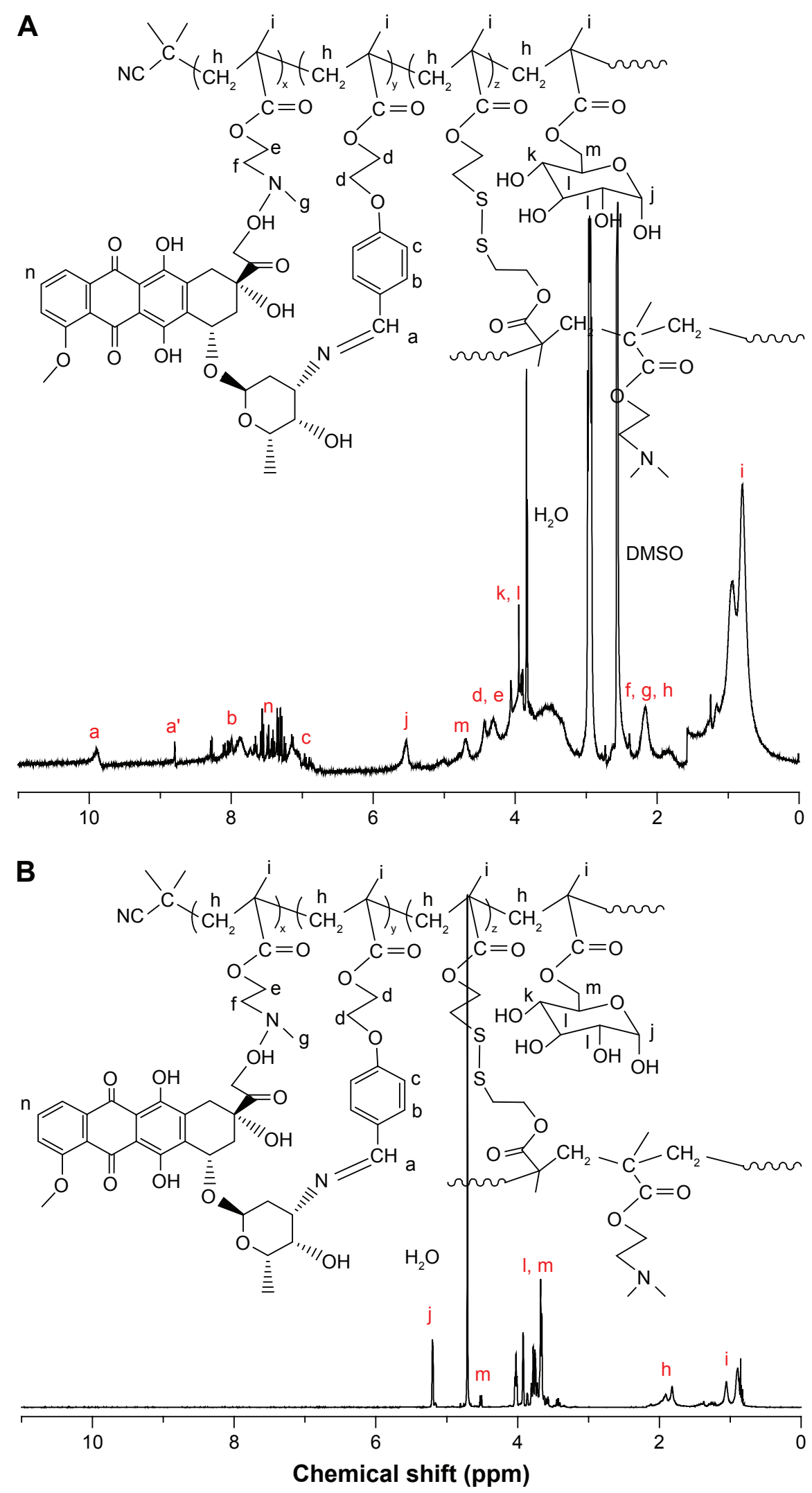

Figure 5 'H-NMR spectra of the BP(DMAEMA-co-MAEBA-co-DTDMA)(PMAGP) ${ }_{n}$-DOX in DMSO (A), and the BP(DMAEMA-co-MAEBA-co-DTDMA)(PMAGP)-DOX in $\mathrm{D}_{2} \mathrm{O}(\mathbf{B})$.

Abbreviations: 'H-NMR, hydrogen-I nuclear magnetic resonance; BP, branched polymer; DTDMA, 2,2'-dithiodiethyoxl dimethacrylate; DMAEMA, 2-(N,Ndimethylaminoethyl)methacrylate; MAEBA, p-(methacryloxyethoxy)benzaldehyde; PMAGP, poly(6-O-methacryloyl-D-galactopyranose); DOX, doxorubicin; DMSO, dimethyl sulfoxide; $\mathrm{D}_{2} \mathrm{O}$, deuterium oxide. 
Table 3 Characteristics of the BP(DMAEMA-co-MAEBA-coDTDMA)(PMAGP) micelles

\begin{tabular}{lllll}
\hline No $^{\mathbf{a}}$ & Precursor & $\mathbf{D}_{\text {DLS }}(\mathbf{n m})^{\mathbf{b}}$ & PDI $^{\mathrm{b}}$ & $\mathbf{D}_{\text {TEM }}(\mathbf{n m})^{\mathbf{c}}$ \\
\hline BSP-HI & BSP-I & 50 & 0.282 & 40 \\
BSP-H2 & BSP-2 & 40 & 0.361 & 30 \\
BSP-H3 & BSP-3 & 55 & 0.142 & 50 \\
\hline
\end{tabular}

Notes: a Hydrolysis of BSP-I, BSP-2, and BSP-3 in $80 \%$ formic acid solution at room temperature for 3 days. ${ }^{\circ} D_{D L s}$ and $\mathrm{PDI}$ are average diameter and size distribution, respectively, of the BP(DMAEMA-co-MAEBA-co-DTDMA)(PMAGP) micelles, which were measured by dynamic light (DLS) scattering method. ${ }^{~} D_{T E M} s$ are average diameters measured by transmission electron microscopy (TEM) method.

Abbreviations: BP(DMAEMA-co-MAEBA-co-DTDMA)(PMAIGP), branched poly (2-(N,N-dimethylaminoethyl)methacrylate-co-p-(methacryloylethoxy)benzaldehyde-co-2,2'-dithiodiethoxyl dimethacrylate)(poly(6-O-methacryloyl-I,2; 3,4di-O-isopropylidene-D-galactopyranose); BSP, branched star polymer; No, number; PMAGP, poly(6-O-methacryloyl-D-galactopyranose); PDI, polydispersity.

(PMAGP) $)_{n}$ was treated with $10 \mathrm{mM}$ DTT in deionized water at room temperature for 48 hours; then, the degraded products were analyzed by GPC. For comparison, GPC traces of both BSP-H3 and its degraded products are shown in Figure 7, and the $M_{\mathrm{w}}$ of the products obtained after treatment with DTT is significantly decreased from $30,600 \mathrm{~g} / \mathrm{mol}$ to $7,600 \mathrm{~g} / \mathrm{mol}$, due to cleavage of the disulfide linkage in the branching units.

\section{In vitro DOX release}

Efficient release of DOX from BSP-H-DOX micelles is crucial for drug delivery systems. Thus, we tested drug release behavior of the BSP-H3-DOX micelles in the PBS solutions at $\mathrm{pH} 5.0,6.0$, and 7.4 , with or without DTT $(10 \mathrm{mM})$, and the results are shown in Figure 8. As described, the imine linkage is acid-labile, and the aromatic imine bond is stable at the physiological $\mathrm{pH}$. When the release was conducted in an aqueous solution at $\mathrm{pH}=7.4$ with or without DTT, almost no DOX in the drugloaded micelles was released, which is consistent with the hydrolysis results of isatin-based aryl imine derivatives. ${ }^{37}$

Table 4 Characterizations of BP(DMAEMA-co-MAEBA-co-DT DMA)(PMAGP) -DOX micelles

\begin{tabular}{llllll}
\hline Sample & $\begin{array}{l}\mathbf{D}_{\text {DLS }} \\
(\mathbf{n m})^{\mathbf{a}}\end{array}$ & PDI $^{\mathrm{b}}$ & $\begin{array}{l}\text { DLC }_{\text {NMR }} \\
\text { (wt\%) }^{\mathbf{c}}\end{array}$ & $\begin{array}{l}\text { DLC }_{\text {Uv }} \\
\text { (wt\%) }^{\mathbf{d}}\end{array}$ & $\begin{array}{l}\text { GE } \\
\text { (wt\%) }^{\mathbf{e}}\end{array}$ \\
\hline BSP-HI-DOX & 90 & 0.221 & 4.67 & 2.1 & 4.46 \\
BSP-H2-DOX & 170 & 0.109 & 6.24 & 4.3 & 5.87 \\
BSP-H3-DOX & 120 & 0.153 & 15.9 & 12.7 & 13.7 \\
\hline
\end{tabular}

Notes: ${ }^{a} D_{D I S}$ refers to average diameters (D) of the BP(DMAEMA-MAEBA-DTDMA) $(P M A G P)_{n}$ micelles, which were measured by DLS method. ${ }^{b} P D I$ refers to size distribution of the micelles as measured by dynamic light scattering (DLS) method; ' $D L C$ refers to drug-loaded content, which was estimated based on 'H-NMR data. 'Determined by ultraviolet (UV) quantitative analysis. ${ }^{\circ}$ Determined by gravimetric method.

Abbreviations: BP(DMAEMA-co-MAEBA-co-DTDMA)(PMAIGP), branched poly (2-(N,N-dimethylaminoethyl)methacrylate-co-p-(methacryloylethoxy) benzaldehyde-co-2,2'-dithiodiethoxyl dimethacrylate)(poly(6-O-methacryloyl-I,2; 3,4-di-O-isopropylidene-D-galactopyranose)n; GE, grafting efficiency; BSP, branched star polymer; NMR, nuclear magnetic resonance; 'H-NMR, hydrogen-I nuclear magnetic resonance; DOX, doxorubicin; PMAGP, poly(6-O-methacryloyl-Dgalactopyranose); PDI, polydispersity; BSP-H-DOX, DOX-loaded product.
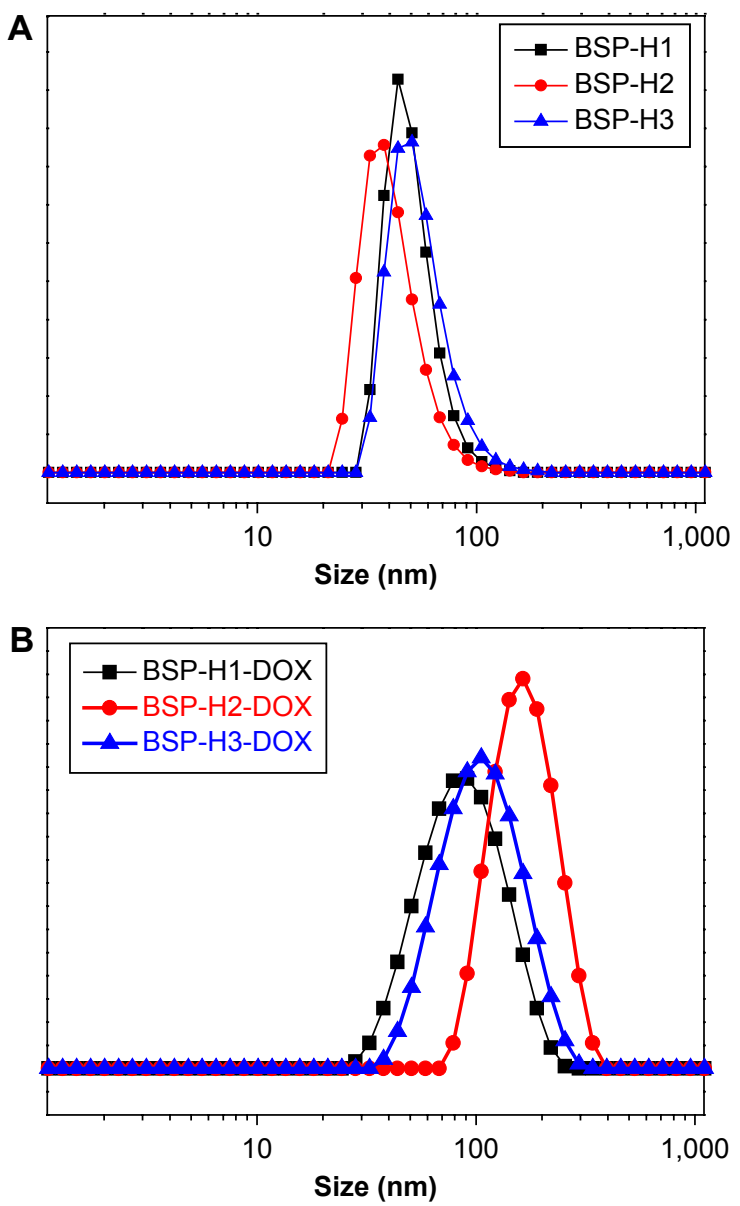

Figure 6 DLS curves of the micelles prepared from BSP-HI, BSP-H2, and BSP-H3 (A), and BSP-H-DOX pro-drug variants (B).

Abbreviations: DLS, dynamic light scattering; BSP, branched star polymer; DOX, doxorubicin.

Obvious contribution of the reducing agent DTT to the drug release was not observed, because DOX is covalently bonded to the polymer chains via aromatic imine linkage, which is stable in the neutral aqueous solution. ${ }^{36-39}$ However, when the release was performed in weak acidic solution, the influence of DTT on the release of DOX was observed; for example, when the release was conducted at $\mathrm{pH}=6.0$ with and without DTT for 48 hours, different release rates were observed: $44 \mathrm{wt} \%$ (with DTT) and 34 wt $\%$ (without DTT) of DOX in micelles were released. The same phenomenon was observed for the release at $\mathrm{pH}=5.0,56 \mathrm{wt} \%$ (with DTT) and $47 \mathrm{wt} \%$ (without DTT) of DOX in the drug carrier were released after 48 hours, because more imine bonds of the MAEBA units were exposed to an acidic environment after degradation of the BSP-H chains, which in turn, accelerated disassembly of the micelles. Acidity of the solution was another important factor influencing release of the drug. When $\mathrm{pH}$ values of the solution decreased from 6.0 to 5.0 with and without DTT, the release rates of DOX from the micelles increased, 


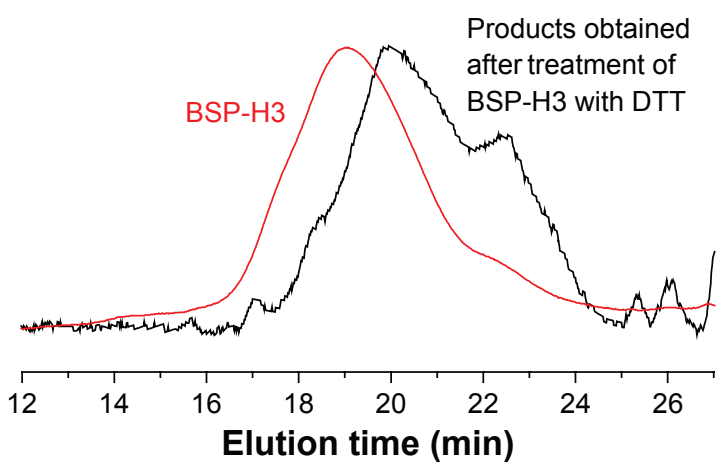

Figure 7 GPC curves of the BP(DMAEMA-co-MAEBA-co-DTDMA)(PMAGP) $)_{n}$ with $M_{\mathrm{n}}=30,600 \mathrm{~g} / \mathrm{mol}(B S P-H 3)$, and the degraded products $\left(M_{\mathrm{n}}=7,600 \mathrm{~g} / \mathrm{mol}\right)$ after BSP-H3 was treated with DTT at room temperature for 48 hours.

Abbreviations: GPC, gel permeation chromatography; BP, branched polymer; BSP, branched star polymer; DTDMA, 2,2'-dithiodiethyoxly dimethacrylate; DMAEMA 2-(N,N-dimethylaminoethyl)methacrylate; MAEBA, p-(methacryloxyethoxy)benzaldehyde; PMAGP, poly(6-O-methacryloyl-D-galactopyranose); DTT, dithiothreitol; min, minutes.

and the amount of DOX released from the drug carriers was enhanced, also shown in Figure 8.

\section{In vitro cytotoxicity assay}

Cytotoxicity of BSP-H and BSP-H-DOX micelles was evaluated by MTT assay, and HepG2 and HeLa cells were used in the current study. The cells were incubated with various concentrations of the $\mathrm{BSP}-\mathrm{H} 3$ micellar solutions at $37^{\circ} \mathrm{C}$ for 24 hours, and the cells treated without the micelles were used as a control. The results in Figure 9 show virtually no toxicity of BP(DMAEMAco-MAEBA-co-DTDMA)(PMAGP) micelles without DOX in the entire concentration range tested to both $\mathrm{HepG} 2$ and $\mathrm{HeLa}$ cells; thus, BSP-H3s are of very low cytotoxicity.

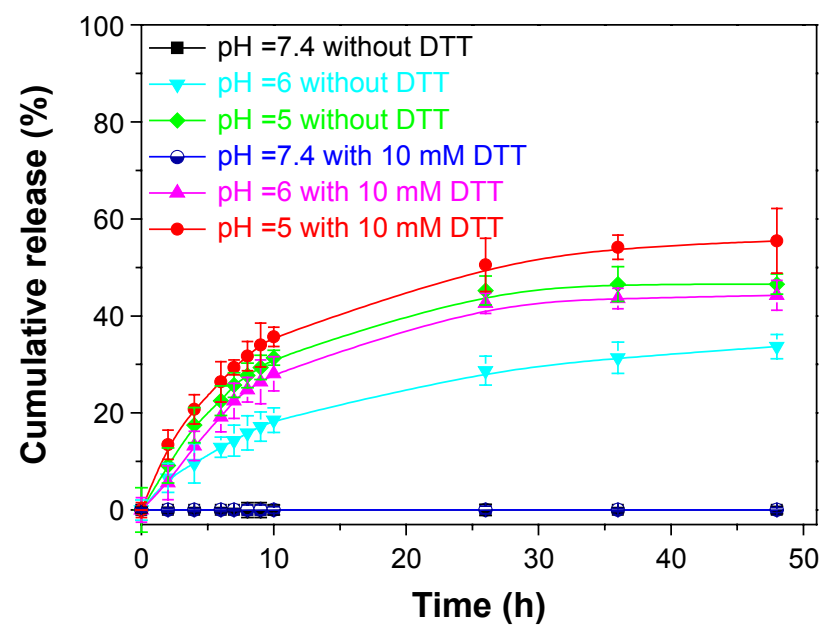

Figure 8 DOX release profiles of the branched star polymer-DOX, BSP-H3-DOX micelles in the aqueous buffer solution under different conditions: at $\mathrm{pH}=7.4$ with and without $10 \mathrm{mM}$ DTT; at $\mathrm{pH}=6.0$ with and without $10 \mathrm{mM} \mathrm{DTT}$; and at $\mathrm{pH}=5.0$ with and without $10 \mathrm{mM}$ DTT.

Note: The dark blue line hides the appearance of the black line in the figure.

Abbreviations: DOX, doxorubicin; DTT, dithiothreitol; h, hours.

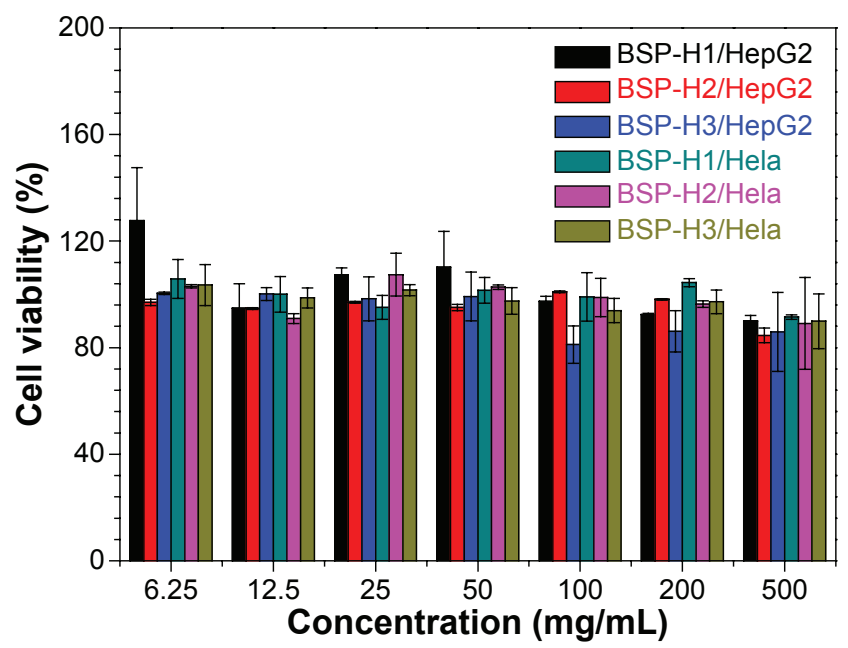

Figure 9 Relative cell viability of HeLa and HepG2 cells evaluated by MTT assay after incubation with micellar solution of the branched star polymers (BSP-HI, BSP$\mathrm{H} 2$, and $\mathrm{BSP}-\mathrm{H} 3)$ at $\mathrm{pH}=7.4$.

Abbreviation: MTT, 3-(4,5-dimethylthiazol-2-YI)-2,5-diphenyltetrazolium bromide.

The cytotoxicity results of free DOX and BSP-H3-DOX are shown in Figure 10. The HepG2 and HeLa cells in solutions of free DOX displayed different dose-response curves, and DOX exhibited higher cytotoxicity to HepG2 cells than to the HeLa cells; for example, DOX doses required for $50 \%$ cellular growth inhibition $\left(\mathrm{IC}_{50}\right)$, evaluated in $\mathrm{HepG} 2$ cells and HeLa cells, were $\sim 0.47 \mu \mathrm{g} / \mathrm{mL}$ and $\sim 1.64 \mu \mathrm{g} / \mathrm{mL}$, respectively. In testing cytotoxicity of the pro-drug, BSP-H3-DOX, to HepG2 and HeLa cells, two different dose-response curves with $\mathrm{IC}_{50}$ values of $50 \mu \mathrm{g} / \mathrm{mL}$ and $6.62 \mu \mathrm{g} / \mathrm{mL}$, respectively, were observed. Since BSP-Hs do not display cytotoxicity (Figure 9), it is reasonable to posit that cytotoxicity of the

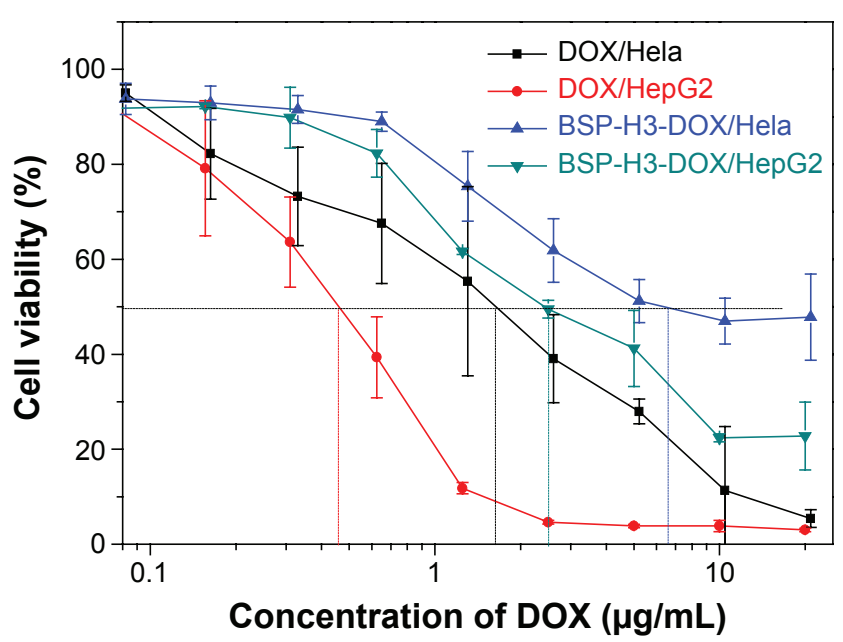

Figure 10 Relative cell viability of HeLa and HepG2 cells evaluated by MTT assay after incubation with solution of the BSP-H3-DOX micelles at $\mathrm{pH}=7.4$ and free $\mathrm{DOX}$ at $\mathrm{pH}=7.4$. Incubating temperature, $37^{\circ} \mathrm{C}$; time, 24 hours.

Abbreviations: MTT, 3-(4,5-dimethylthiazol-2-YI)-2,5-diphenyltetrazolium bromide; $\mathrm{BSP}$, branched star polymer; DOX, doxorubicin. 
A

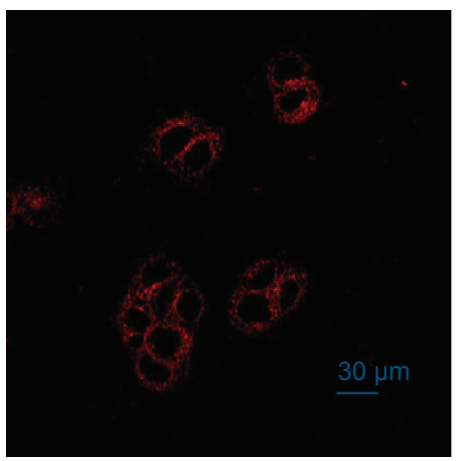

B

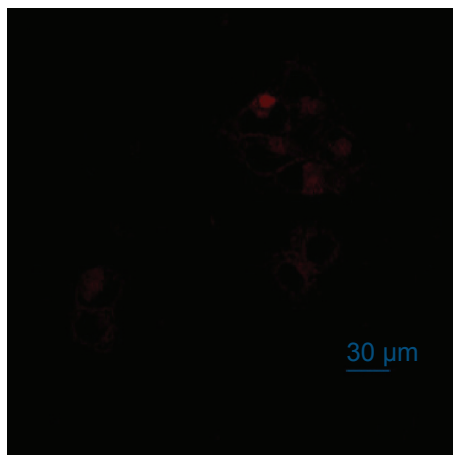

A1

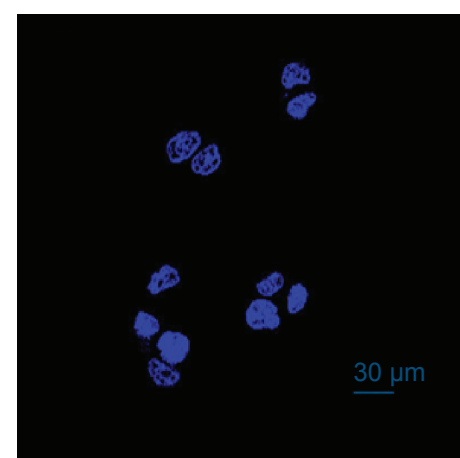

B1

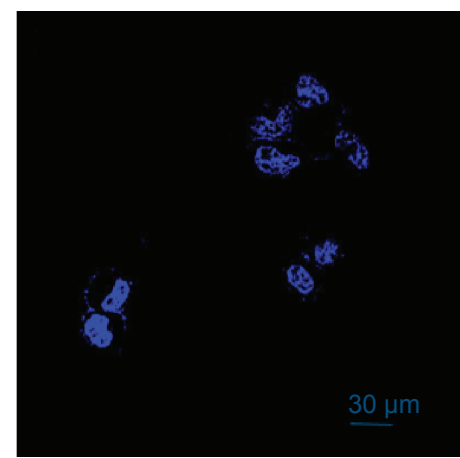

A2

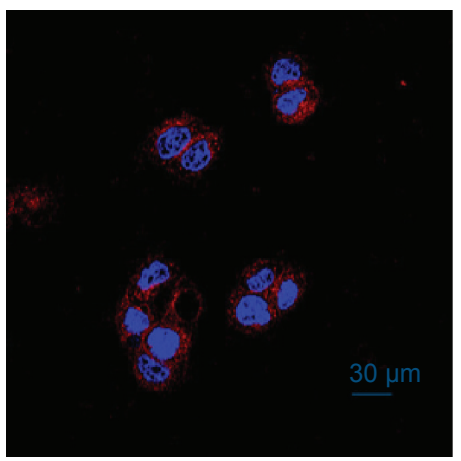

B2

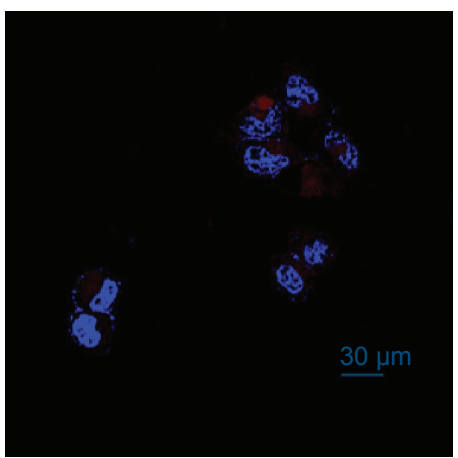

Figure II Confocal laser scanning microscope images of the HepG2 cells (A) and the HeLa cells (B) treated with the BSP-H3-DOX micelle solution (AI and BI) and stained with DAPI (A2 and B2) at $37^{\circ} \mathrm{C}$ for 4 hours for each panel; the images, from left to right, show DOX (red), DAPI (blue), and a merge of the two images (far right, red and blue).

Abbreviations: BSP, branched star polymer; DOX, doxorubicin; DAPI, 2-(4-amidinophenyl)-6-indolecarbamidine dihydrochloride.

pro-drug comes from release of DOX in the micelles. In addition, HSP-H3-DOX micelles showed higher cytotoxicity to HepG2 cells compared to HeLa cells.

\section{Cellular uptake}

The cellular uptake efficiency of HSP-H-DOX micelles was further studied by CLSM. HepG2 cells and HeLa cells were incubated with the same dose of the HSP-H3-DOX micelles for 4 hours, and then were stained with DAPI. CLSM images in Figure 11 reveal that DOX red fluorescence appears at the perinuclear region of HepG2 cells, and that DAPI blue fluorescence is located at the nucleus, suggesting successful internalization of the micelles within the cells. Moreover, DOX red fluorescence in HeLa cells (Figure 11B1) is relatively weak in comparison with that in HepG2 cells (Figure 11B1). As discussed, galactose is a specific liver-targeting ligand ${ }^{51,52}$ the periphery polymers, PMAGPs, contain a number of galactose groups, and therefore, HSP-HDOXs can be easily internalized by HepG2 cells compared to HeLa cells.

\section{Conclusion}

In the current study, amphiphilic branched star copolymers, BP(DMAEMA-co-MAEBA-co-DTDMA)(PMAGP) ${ }_{n}$ s, which possess $\mathrm{pH}$ - and redox-responsive properties, have been successfully synthesized by RAFT polymerization, and the anti-cancer drug, DOX, has been linked to the branched copolymers, BP(DMAEMA-co-MAEBA-co-DTDMA)s, by condensation reaction of primary amine of DOX with aldehyde groups of the polymer chains. The resultant DOXcontaining BSP-Hs can be self-assembled in water, forming DOX-loaded spherical micelles. Aromatic imine linkage is quite stable in neutral water, but is $\mathrm{pH}$-sensitive, and controlled release of DOX from BSP-H-DOX micelles is achieved under weak acidic condition $(\mathrm{pH}=5$ and 6$)$. Degradation of branched star copolymers under DTT can accelerate release of the drug in micelles. Experimental results in vitro reveal almost no cytotoxicity of BP(DMAEMA-coMAEBA-co-DTDMA)(PMAGP) ${ }_{\mathrm{n}} \mathrm{s}$ in the current study, and the release of DOX in HepG2 and HeLa cells was observed. DOX-loaded micelles displayed specific binding to HepG2 cells, due to galactosyl groups on the periphery of micelles. Thus, this kind of polymer micelle can act as a hepatomatargeting drug delivery vehicle.

\section{Acknowledgments}

This work was supported by National Natural Science Foundation of China under contract numbers 21090354 
and 21374107 , and was also supported by the Fundamental Research Funds for the Central Universities (grant number WK 2060200012).

\section{Disclosure}

The authors report no conflicts of interest in this work.

\section{References}

1. Phillips MA, Gran ML, Peppas NA. Targeted nanodelivery of drugs and diagnostics. Nano Today. 2010;5:143-159.

2. Liu S, Maheshwari R, Kiick KL. Polymer-based therapeutics. Macromolecules. 2009;42:3-13.

3. Peer D, Karp JM, Hong S, Farokhzad OC, Margalit R, Langer R. Nanocarriers as an emerging platform for cancer therapy. Nat Nanotechnol. 2007;2:751-760

4. Kim BS, Park SW, Hammond PT. Hydrogen-bonding layer-by-layerassembled biodegradable polymeric micelles as drug delivery vehicles from surfaces. ACS Nano. 2008;2:386-392.

5. Torchilin VP. Multifunctional nanocarriers. Adv Drug Deliv Rev. 2006; $58: 1532-1555$.

6. Kataoka K, Harada A, Nagasaki Y. Block copolymer micelles for drug delivery: design, characterization and biological significance. Adv Drug Deliv Rev. 2001;47:113-131.

7. Su W, Luo XH, Wang HF, et al. Hyperbranched polycarbonate-based multimolecular micelle with enhanced stability and loading efficiency. Macromol Rapid Commun. 2011;32:390-396.

8. Zhou Y, Yan D. Supramolecular self-assembly of amphiphilic hyperbranched polymers at all scales and dimensions: progress, characteristics and perspectives. Chem Commun (Camb). 2009;10:1172-1188.

9. Meng F, Zhong Z, Feijen J. Stimuli-responsive polymersomes for programmed drug delivery. Biomacromolecules. 2009;10:197-209.

10. Guo X, Shi C, Wang J, Di S, Zhou S. pH-triggered intracellular release from actively targeting polymer micelles. Biomaterials. 2013;34:4544-4554.

11. Shi C, Guo X, Qu Q, Tang Z, Wang Y, Zhou S. Actively targeted delivery of anticancer drug to tumor cells by redox-responsive star-shaped micelles. Biomaterials. 2014;35:8711-8722.

12. Duncan R. The dawning era of polymer therapeutics. Nat Rev Drug Discov. 2003;2:347-360.

13. Wang Y, Hong CY, Pan CY. Spiropyran-based hyperbranched star copolymer: synthesis, phototropy, FRET, and bioapplication. Biomacromolecules. 2012;13:2585-2893.

14. Lee CC, MacKay JA, Frechet JM, Szoka FC. Designing dendrimers for biological applications. Nature Biotechnol. 2005;23: 1517-1526.

15. Medina SH, El-Sayed ME. Dendrimers as carriers for delivery of chemotherapeutic agents. Chem Rev. 2009;109:3141-3157.

16. Fox ME, Szoka FC, Fréchet JM. Soluble polymer carriers for the treatment of cancer: the importance of molecular architecture. Acc Chem Res. 2009;42:1141-1151.

17. Liu J, Pang Y, Huang W, et al. Bioreducible micelles self-assembled from amphiphilic hyperbranched multiarm copolymer for glutathione-mediated intracellular drug delivery. Biomacromolecules. 2011;12:1567-1577.

18. Shi F, Ding J, Xiao C, et al. Intracellular microenvironment responsive PEGylated polypeptide nanogels with ionizable cores for efficient doxorubicin loading and triggered release. J Mater Chem. 2012;22: 14168-14179.

19. Kong SD, Sartor M, Hu CM, Zhang W, Zhang L, Jin S. Magnetic field activated lipid-polymer hybrid nanoparticles for stimuli-responsive drug release. Acta Biomater. 2013;9:5447-5452.

20. Dai M, Xu X, Song J, et al. Preparation of camptothecin-loaded PCEC microspheres for the treatment of colorectal peritoneal carcinomatosis and tumor growth in mice. Cancer Lett. 2011;312:189-196.

21. Johnson JA, Lu YY, Burts AO, et al. Drug-loaded, bivalent-bottle-brush polymers by graft-through ROMP. Macromolecules. 2010;43:10326-10335.
22. Cheetham AG, Zhang P, Lin YA, Lock LL, Cui H. Supramolecular nanostructures formed by anticancer drug assembly. J Am Chem Soc. 2013; 135:2907-2910.

23. Cho JK, Chun C, Kuh HJ, Song SC. Injectable poly(organophosphazene)camptothecin conjugate hydrogels: synthesis, characterization, and antitumor activities. Eur J Pharm Biopharm. 2012;81:582-590.

24. Wang Y, Hong CY, Pan CY. Galactose-based amphiphilic block copolymers: synthesis, micellization, and bioapplication. Biomacromolecules. 2013;14:1444-1451.

25. Ding J, Xu W, Zhang Y, et al. Self-reinforced endocytoses of smart polypeptide nanogels for "on-demand" drug delivery. J Control Release. 2013;172:444-455.

26. Lynn DM, Amiji MM, Langer R. pH-responsive polymer microspheres: rapid release of encapsulated material within the range of intracellular pH. Angew Chem Int Ed Engl. 2001;40:1707-1710.

27. Lee S, Saito K, Lee HR, et al. Hyperbranched double hydrophilic block copolymer micelles of poly(ethylene oxide) and polyglycerol for pH-responsive drug delivery. Biomacromolecules. 2012;13: 1190-1196.

28. Zhan F, Chen W, Wang Z, et al. Acid-activatable prodrug nanogels for efficient intracellular doxorubicin release. Biomacromolecules. 2011; 12:3612-3620.

29. Bae Y, Jang WD, Nishiyama N, Fukushima S, Kataoka K. Multifunctional polymeric micelles with folate-mediated cancer cell targeting and $\mathrm{pH}$-triggered drug releasing properties for active intracellular drug delivery. Mol Biosyst. 2005;1:242-250.

30. Tang X, Pan CY. Double hydrophilic block copolymers PEO-b-PGA: synthesis, application as potential drug carrier and drug release via pH-sensitive linkage. J Biomed Mater Res A. 2008;86:428-438.

31. Gillies ER, Fréchet JM. pH-responsive copolymer assemblies for controlled release of doxorubicin. Bioconjug Chem. 2005;16:361-368.

32. Jaeger DA, Sayed YM. Synthesis and characterization of singlechain second generation cleavable surfactants. J Org Chem. 1993;58: 2619-2627.

33. Xu S, Luo Y, Haag R. Water-soluble pH-responsive dendritic core-shell nanocarriers for polar dyes based on poly(ethylene imine). Macromol Biosci. 2007;7:968-974.

34. Lemieux GA, Bertozzi CR. Chemoselective ligation reactions with proteins, oligosaccharides and cells. Trends Biotechnol. 1998;16: 506-513.

35. Kaneko T, Willner D, Monkovíc I, et al. New hydrazone derivatives of adriamycin and their immunoconjugates - a correlation between acid stability and cytotoxicity. Bioconj Chem. 1991;2:133-141.

36. Ding C, Gu J, Qu X, Yang Z. Preparation of multifunctional drug carrier for tumor-specific uptake and enhanced intracellular delivery through the conjugation of weak acid labile linker. Bioconj Chem. 2009;20:1163-1170.

37. Matesic L, Locke JM, Vine KL, Ranson M, Bremner JB, Skropeta D. Synthesis and hydrolytic evaluation of acid-labile imine-linked cytotoxic isatin model systems. Bioorg Med Chem. 2011;19:1771-1778.

38. Müller IA, Kratz F, Jung M, Warnecke A. Schiff bases derived from p-aminobenzyl alcohol as trigger groups for $\mathrm{pH}$-dependent prodrug activation. Tetrahedron Lett. 2010;51:4371-4374.

39. Sedlák M, Pravda M, Staud F, Kubicová L, Týcová K, Ventura K. Synthesis of pH-sensitive amphotericin B-poly(ethylene glycol) conjugates and study of their controlled release in vitro. Bioorg Med Chem. 2007;15:4069-4076.

40. Xu X, Flores JD, McCormick CL. Reversible imine shell cross-linked micelles from aqueous RAFT-synthesized thermoresponsive triblock copolymers as potential nanocarriers for " $\mathrm{pH}$-triggered" drug release. Macromolecules. 2011;44:1327-1334.

41. Kim YH, Park JH, Lee M, Kim YH, Park TG, Kim SW. Polyethylenimine with acid-labile linkages as a biodegradable gene carrier. J Control Release. 2005;103:209-219.

42. Jackson AW, Fulton DA. pH triggered self-assembly of core crosslinked star polymers possessing thermoresponsive cores. Chem Commun (Camb). 2011;47:6807-6809. 
43. Jackson AW, Stakes C, Fulton DA. The formation of core cross-linked star polymer and nanogel assemblies facilitated by the formation of dynamic covalent imine bonds. Polym Chem. 2011;2:2500-2511.

44. Murray BS, Jackson AW, Mahon CS, Fulton DA. Reactive thermoresponsive copolymer scaffolds. Chem Commun (Camb). 2010;46: 8651-8653.

45. Hu X, Li H, Luo S, Liu T, Jiang Y, Liu S. Thiol and pH dual-responsive dynamic covalent shell cross-linked micelles for triggered release of chemotherapeutic drugs. Polym Chem. 2013;4:695-706.

46. Hu X, Tian J, Liu T, Zhang G, Liu S. Photo-triggered release of caged camptothecin prodrugs from dually responsive shell cross-linked micelles. Macromolecules. 2013;46:6243-6256.

47. Hong CY, You YZ, Liu J, Pan CY. Dendrimer-star polymer and block copolymer prepared by reversible addition-fragmentation chain transfer (RAFT) polymerization with dendritic chain transfer agent. J Polym Sci Part A: Polym Chem. 2005;43:6379-6393.

48. Zheng Q, Pan CY. Synthesis and characterization of dendrimer-star polymer using dithiobenzoate-terminated poly(propylene imine) dendrimer via reversible addition-fragmentation transfer polymerization. Macromolecules. 2005;38:6841-6848.

49. Yang HJ, Jiang BB, Huang WY, et al. Development of branching in atom transfer radical copolymerization of styrene with triethylene glycol dimethacrylate. Macromolecules. 2009;42:5976-5982.

50. Sun M, Pan CY. Formation of hyperbranched polymers in atom transfer radical copolymerization of MMA and DVB. Sci China Chem. 2010; $53: 2440-2451$.
51. Mamidyala SK, Dutta S, Chrunyk BA, et al. Glycomimetic ligands for the human asialoglycoprotein receptor. J Am Chem Soc. 2012;134: 1978-1981.

52. Mi FL, Wu YY, Chiu YL, et al. Synthesis of a novel glycoconjugated chitosan and preparation of its derived nanoparticles for targeting HepG2 cells. Biomacromolecules. 2007;8:892-898.

53. Sedlák M, Pravda M, Kubicová L, Mikulcíková P, Ventura K. Synthesis and characterisation of a new $\mathrm{pH}$-sensitive amphotericin B-poly(ethylene glycol)-b-poly(L-lysine) conjugate. Bioorg Med Chem Lett. 2007; 17:2554-2557.

54. Cartoni A, Menna P, Salvatorelli E, et al. Oxidative degradation of cardiotoxic anticancer anthracyclines to phthalic acids. Novel function or ferrylmyoglobin. J Biol Chem. 2004;279:5088-5099.

55. Zhang L, Eisenberg A. Formation of crew-cut aggregates of various morphologies from amphiphilic block copolymers in solution. Polym Adv Technol. 1998;9:677-699.

56. Balendiran GK, Dabur R, Fraser D. The role of glutathione in cancer. Cell Biochem Funct. 2004;22:343-352.

57. Xie LL, Xu JQ, Gao CY. Multilayers and poly(allylamine hydrochloride)graft-poly(ethylene glycol) modified bovine serum albumin nanoparticles: improved stability and $\mathrm{pH}$-responsive drug delivery. Chinese J Polym Sci. 2012;30:719-726.

58. Yang W, Pan CY, Liu XQ, Wang J. Multiple functional hyperbranched poly(amido amine) nanoparticles: synthesis and application in cell imaging. Biomacromolecules. 2011;12:1523-1531. 


\section{Supplementary materials}

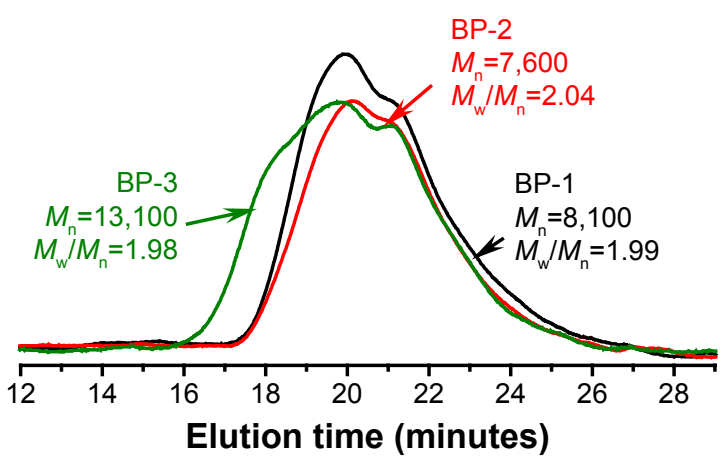

Figure SI GPC curves of the branched polymers, BP(DMAEMA-MAEBA DTDMA)-I (BP-I), BP(DMAEMA-MAEBA-DTDMA)-2 (BP-2), and BP(DMAEMAMAEBA-DTDMA)-3 (BP-3) prepared by RAFT copolymerization at $70^{\circ} \mathrm{C}$ for 24 hours with feed molar ratios of [DMAEMA]:[MAEBA]:[DTDMA]:[CPDA]:[AIB $\mathrm{N}]=36: 4: 1.5: 1: 0.25,32: 8: 1.5: 1: 0.25$, and 16:24:1.5:1:0.25, respectively.

Abbreviations: GPC, gel permeation chromatography; BP, branched polymer; DTDMA, 2,2'-dithiodiethyoxly dimethacrylate; DMAEMA, 2-(N,N-dimethylaminoethyl)methacrylate; MAEBA, p-(methacryloxyethoxy)benzaldehyde; RAFT, reversible addition-fragmentation chain transfer; CPDB, cyanoisopropyl dithiobenzoate; AIBN, Azobis (isobutyronitrile).
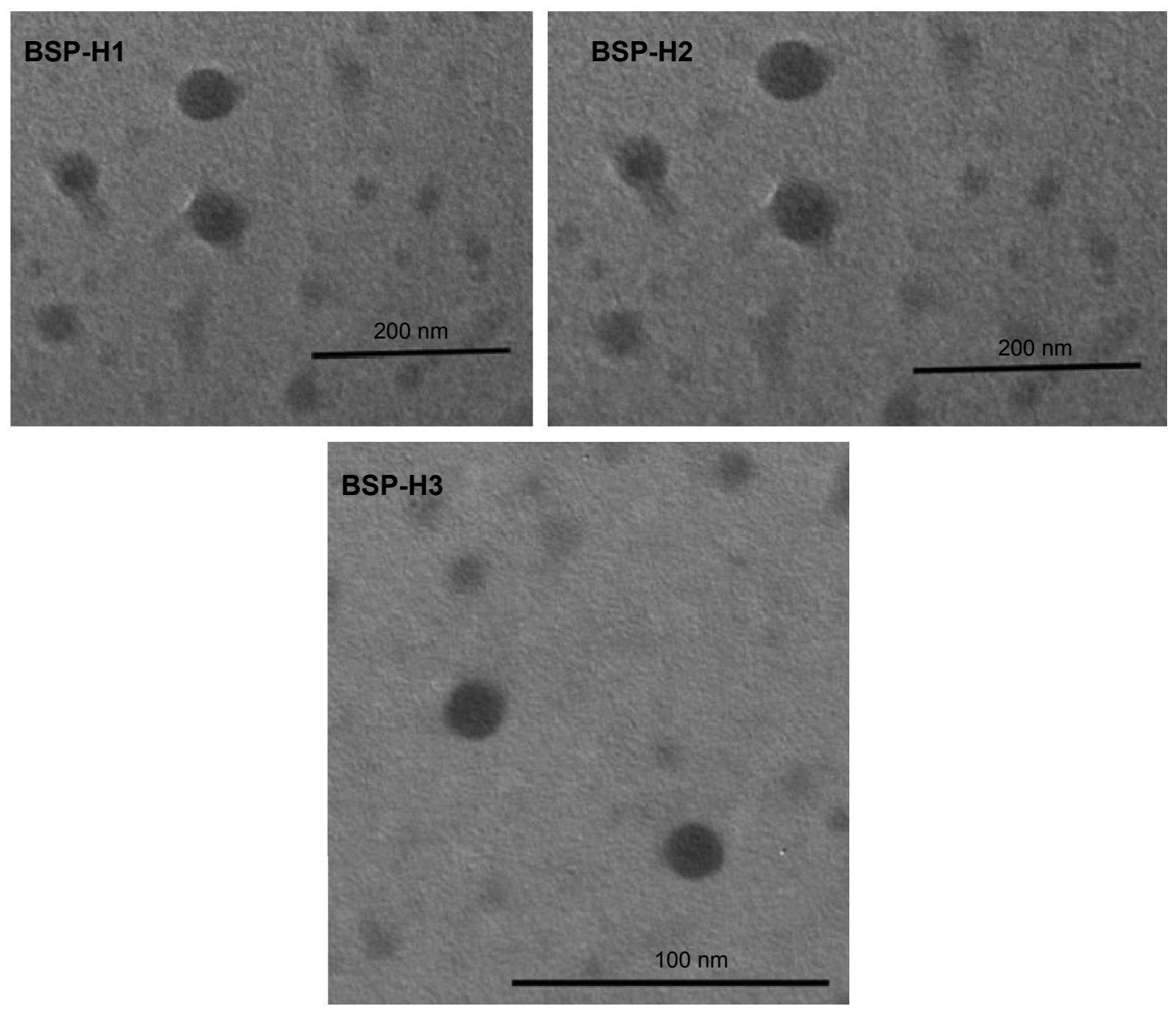

Figure S3 TEM images of the micelles prepared respectively from BSP-HI to BSP-H3.

Abbreviations: TEM, transmission electron microscopy; BSP, branched star polymer.

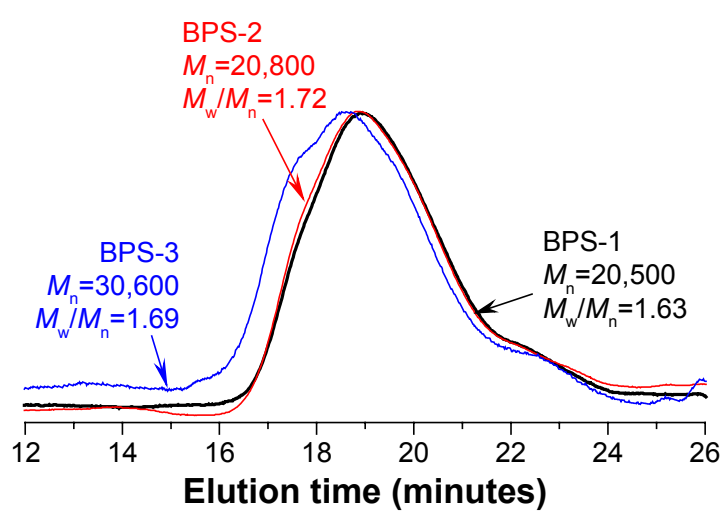

Figure S2 GPC curves of the branched star polymers (BSPs), BP(DMAEMAMAEBA-DTDMA) I (PMAIGP) (BSP-I), BP(DMAEMA-MAEBA-DTDMA)2(PMAIGP) (BSP-2), and BP(DMAEMA-MAEBA-DTDMA)3(PMAIGP) ${ }_{n}$ (BSP-3) prepared by RAFT polymerization of MAIGP at $70^{\circ} \mathrm{C}$ for 24 hours with the feed molar ratios of [MAIGP]:[BP-1 or BP-2 or BP-3] =100:1.

Abbreviations: GPC, gel permeation chromatography; BP, branched polymer; DTDMA, 2,2'-dithiodiethyoxly dimethacrylate; DMAEMA, 2-(N,N-dimethylaminoethyl)methacrylate; MAEBA, P-(methacryloxyethoxy)benzaldehyde; RAFT, reversible addition-fragmentation chain transfer; $C P D B$, cyanoisopropyl dithiobenzoate; AIBN, Azobis(isobutyronitrile); MAIGP, poly(6-O-methacryloyl-I,2; 3,4-diO-isopropylidene-D-galactopyranose. 

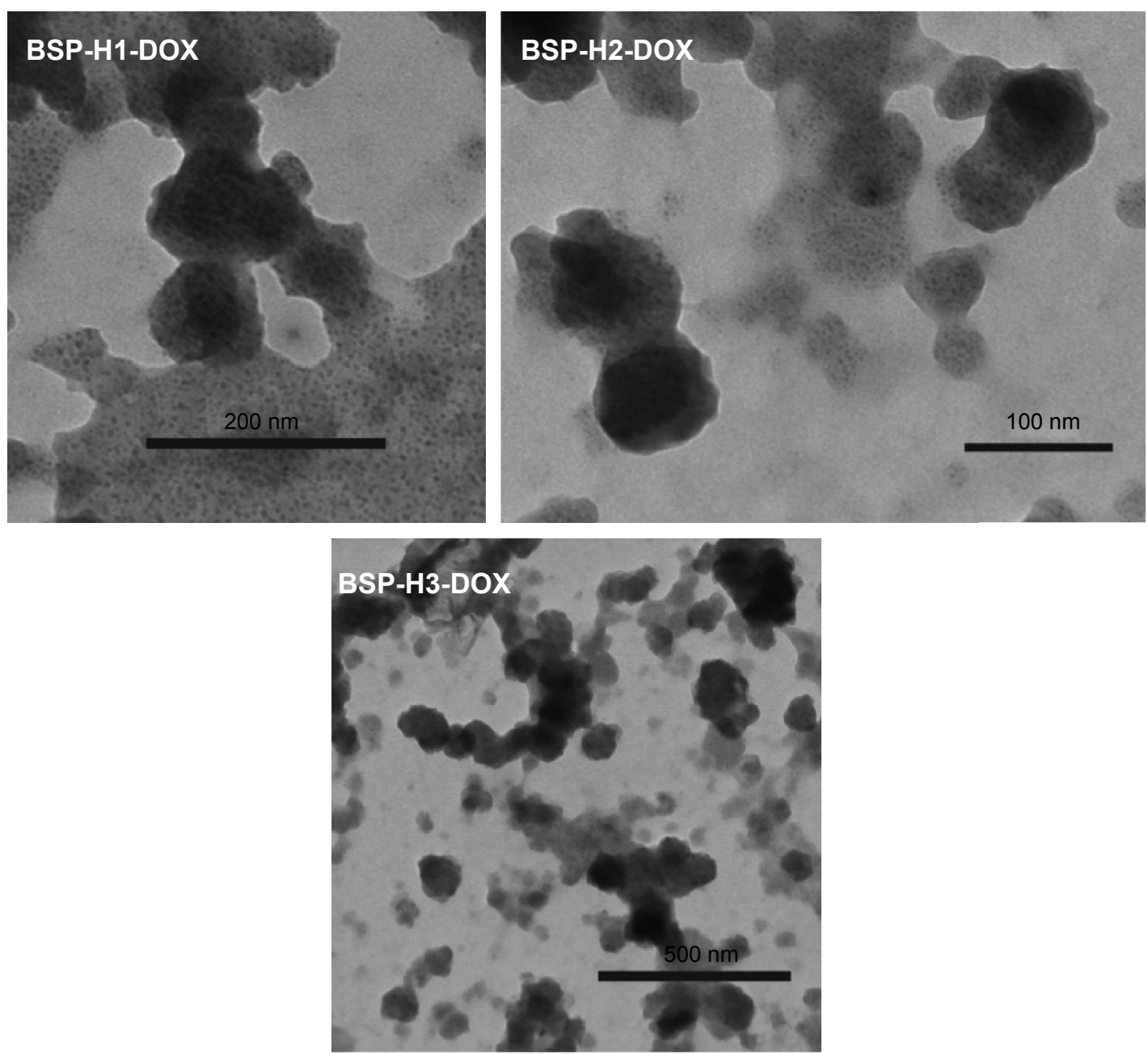

Figure S4 TEM images of BSP-H-DOX pro-drug.

Abbreviations: TEM, transmission electron microscopy; BSP, branched star polymer; DOX, doxorubicin.

International Journal of Nanomedicine

\section{Publish your work in this journal}

The International Journal of Nanomedicine is an international, peerreviewed journal focusing on the application of nanotechnology in diagnostics, therapeutics, and drug delivery systems throughout the biomedical field. This journal is indexed on PubMed Central, MedLine, CAS, SciSearch ${ }^{\circledR}$, Current Contents ${ }^{\circledR} /$ Clinical Medicine,

\section{Dovepress}

Journal Citation Reports/Science Edition, EMBase, Scopus and the Elsevier Bibliographic databases. The manuscript management system is completely online and includes a very quick and fair peer-review system, which is all easy to use. Visit http://www.dovepress.com/ testimonials.php to read real quotes from published authors.

Submit your manuscript here: http://www.dovepress.com/international-journal-of-nanomedicine-journal 